\title{
Behavioral and Neurochemical Alterations in Mice Lacking the RNA-Binding Protein Translin
}

\author{
Joel M. Stein, ${ }^{1}$ Wayland Bergman, ${ }^{2}$ Yanshan Fang, ${ }^{1}$ LaKesha Davison, ${ }^{1}$ Colleen Brensinger, ${ }^{3}$ Michael B. Robinson, ${ }^{2}$ \\ Norman B. Hecht, ${ }^{4}$ and Ted Abel ${ }^{1}$ \\ ${ }^{1}$ Department of Biology, University of Pennsylvania, Philadelphia, Pennsylvania 19104, ${ }^{2}$ Departments of Pediatrics and Pharmacology, Children's Hospital \\ of Philadelphia, University of Pennsylvania, Philadelphia, Pennsylvania 19104, and Centers for ${ }^{3}$ Clinical Epidemiology and Biostatistics and ${ }^{4}$ Research on \\ Reproduction and Women's Health, University of Pennsylvania School of Medicine, Philadelphia, Pennsylvania 19104
}

Synapse-specific local protein synthesis is thought to be important for neurodevelopment and plasticity and involves neuronal RNAbinding proteins that regulate the transport and translation of dendritically localized transcripts. The best characterized of these RNAbinding proteins is the fragile X mental retardation protein (FMRP). Mutations affecting the expression or function of FMRP cause fragile $\mathrm{X}$ syndrome in humans, and targeted deletion of the gene encoding FMRP results in developmental and behavioral alterations in mice. Translin is an RNA-binding protein that regulates mRNA transport and translation in mouse male germ cells and is proposed to play a similar role in neurons. Like FMRP, translin is present in neuronal dendrites, binds dendritically localized RNA, and associates with microtubules and motor proteins. We reported previously the production of viable homozygous translin knock-out mice, which demonstrate altered expression of multiple mRNA transcripts in the brain and mild motor impairments. Here, we report that translin knock-out mice also exhibit sex-specific differences in tests of learning and memory, locomotor activity, anxiety-related behavior, and sensorimotor gating, as well as handling-induced seizures and alterations in monoamine neurotransmitter levels in several forebrain regions. Similar behavioral and neurochemical alterations have been observed in mice lacking FMRP, suggesting that both proteins may act within the same neuronal systems and signaling pathways. Our results in mice indicate that mutations in translin may contribute to fragile X-like syndromes, mental retardation, attention deficit hyperactivity disorder, epilepsy, and autism spectrum disorders in humans.

Key words: anxiety; attention; RNA trafficking; local translation; fragile X syndrome; norepinephrine

\section{Introduction}

Dendritic protein synthesis involves cis-acting targeting sequences in localized mRNAs and trans-acting RNA-binding proteins that regulate the storage, transport, translation, and degradation of these mRNAs. Genetically disrupting the targeting sequence of calcium/calmodulin kinase II $\alpha$ (CaMKII $\alpha$ ) mRNA prevents its accumulation in hippocampal dendrites in mice and produces deficits in the Morris water maze and contextual fear conditioning, two hippocampus-dependent memory tasks (Miller et al., 2002). Mice lacking fragile X mental retardation protein (FMRP), the most extensively studied trans-acting factor, exhibit altered levels of dendritic mRNAs (Zalfa et al., 2003) and multiple behavioral phenotypes, including subtle water maze

Received 0ct. 18, 2005; revised Dec. 19, 2005; accepted Jan. 12, 2006.

This work was supported by National Institutes of Health Institutional National Research Service Award Training Grant T32 AG00256 (J.M.S.; Allan Pack, principal investigator), Conte Center for Neuroscience and Mental Disorders Grant P50 MH 6404501 (T.A.; R. Gur, principal investigator), a David and Lucille Packard Foundation fellowship (T.A.), National Institute of Mental Health Grant R01 MH 060244 (T.A.), and National Institutes of Health Grant HD 28832 (N.B.H.). The HPLC core facility at the Children's Hospital of Philadelphia is partially supported by Institutional Mental Retardation and Developmental Disabilities Research Center Grant P30 HD 026979. We thank Mark Geyer for advice regarding sensorimotor gating, Yiqing Liang for assistance with zero maze software analysis, Felix Yelin for help with neurochemical measurements, and Marcelo Wood for helpful comments and discussions.

Correspondence should be addressed to Ted Abel, Department of Biology, University of Pennsylvania, 319 Leidy Labs, 38th and Hamilton Walk, Philadelphia, PA 19104. E-mail: abele@sas.upenn.edu.

D0I:10.1523/JNEUROSCI.4437-05.2006

Copyright $\odot 2006$ Society for Neuroscience $\quad 0270-6474 / 06 / 262184-13 \$ 15.00 / 0$ deficits, hyperactivity, decreased anxiety-related behavior, mild motor impairments on the rotarod test, reduced acoustic startle responses, enhanced prepulse inhibition (PPI) of startle, and increased susceptibility to audiogenic seizures (Bakker et al., 1994; D’Hooge et al., 1997; Paradee et al., 1999; Peier et al., 2000; Chen and Toth, 2001; Mineur et al., 2002; Qin et al., 2002; Frankland et al., 2004). Mice lacking FXR2, a homolog of FMRP, exhibit water maze and contextual fear conditioning deficits, hyperactivity, rotarod impairments, and reduced prepulse inhibition (Bontekoe et al., 2002).

The current study explores the consequences of disrupting translin (also known as testis-brain RNA-binding protein), a protein thought to regulate mRNA transport and translation that shares many features with FMRP. Like FMRP, translin shows highest expression in the testis and brain (Han et al., 1995b; Hergersberg et al., 1995; Gu et al., 1998; Finkenstadt et al., 2001). In the testis, translin binds translationally repressed mRNAs containing cis-acting motifs termed $\mathrm{Y}$ and $\mathrm{H}$ elements and accompanies these transcripts along intercellular bridges between spermatids (Morales et al., 2002). In the brain, translin binds CaMKII $\alpha$ and the untranslated RNA BC1 (Kobayashi et al., 1998; Severt et al., 1999; Wu and Hecht, 2000), dendritically localized RNAs that also associate with FMRP (Zalfa et al., 2003). Both proteins exhibit a somatodendritic distribution in neurons (Feng et al., 1997; Kobayashi et al., 1998; Muramatsu et al., 1998; Wu et al., 1999; 
Finkenstadt et al., 2000), shuttle between the nucleus and cytoplasm (Feng et al., 1997; Morales et al., 2002), interact with microtubules and motor proteins (Han et al., 1995a; Wu and Hecht, 2000; Ohashi et al., 2002; Antar et al., 2005), repress translation (Kwon and Hecht, 1993; Laggerbauer et al., 2001; Li et al., 2001; Yang et al., 2003), and may be involved in RNA interference (Caudy et al., 2002; Ishizuka et al., 2002; Wang et al., 2004).

We reported previously the production of homozygous translin knock-out (KO) mice, which exhibit reduced growth, increased visceral adipose tissue, normal fertility but abnormal spermatogenesis, downregulation of multiple brain mRNAs, and mild impairments in the rotarod task (Chennathukuzhi et al., 2003). Given in vitro evidence that translin mediates the dendritic localization of CaMKII $\alpha$ (Severt et al., 1999), we hypothesized that translin $\mathrm{KO}$ mice would exhibit deficits in the Morris water maze and contextual fear conditioning. Considering the many similarities between translin and FMRP, we suspected that translin $\mathrm{KO}$ mice might show more subtle learning differences and alterations in activity, anxiety-related behavior, and sensorimotor gating.

\section{Materials and Methods}

Animals. The generation of translin $\mathrm{KO}$ mice and their genotyping by PCR amplification of tail DNA was described previously (Chennathukuzhi et al., 2003). translin $\mathrm{KO}$ mice were successively backcrossed to C57BL/6J inbred mice to minimize genetic variability. The C57BL/6J strain was chosen because it breeds well and exhibits average performance in tests of learning, activity, anxiety-related behavior, and sensorimotor gating (Crawley et al., 1997). After transmission of the targeted translin allele through three crosses to C57BL/6J mice, heterozygous N3 animals were mated to produce homozygous translin $\mathrm{KO}$ mice and wildtype (WT) littermates for all studies. Mice were segregated by sex, housed four to five to a cage, provided with water and rodent chow ad libitum, and maintained on a $12 \mathrm{~h}$ light/dark cycle. All experiments were performed during the light cycle using translin $\mathrm{KO}$ mice and WT littermate controls between 2 and 6 months of age and were conducted in accordance with the policies of the Institutional Animal Care and Use Committee of the University of Pennsylvania and the National Institutes of Health.

Water maze. Spatial learning and memory was tested in the water maze task originally developed by Morris et al. (1982) and adapted for mice as described previously (Lattal and Abel, 2001). Mice were trained to find a circular, submerged platform in a pool of water made opaque with nontoxic white tempera paint. The pool and the platform diameters were 117 and $11 \mathrm{~cm}$, respectively. Distal spatial cues were placed around the room away from the edge of the pool, and the platform was placed in one of two locations on opposite sides of the pool. During acquisition training, each mouse received four trials per day on 6 consecutive days, with a maximum trial length of $60 \mathrm{~s}$ and intertrial intervals of $4-6 \mathrm{~min}$. The latency to find the hidden platform during each trial was recorded. At the end of each trial, mice were left on the platform for $20 \mathrm{~s}$ before being returned to their home cages. During reversal testing, mice received four trials per day for $3 \mathrm{~d}$, with the platform switched to the opposite side of the pool. During visible training, mice received four trials per day for $4 \mathrm{~d}$, the platform was moved to one of four locations between each trial, and a marker extending above the pool surface indicated the platform position. Probe trials, in which the platform was removed and mice were allowed to search the pool for $60 \mathrm{~s}$, were performed after acquisition and reversal training, on days 7 and 11 of testing, respectively. Each trial was recorded using an overhead CCD camera and video tracking software (HVS Image, Buckingham, UK), allowing for measurements of quadrant preference, swim speed, and thigmotaxis (swimming around the periphery of the pool within $6 \mathrm{~cm}$ of the wall).

Cued and contextual fear conditioning. Fear conditioning experiments were performed as described previously (Nie and Abel, 2001). Mice were trained to associate an auditory conditioned stimulus (CS) (white noise at $85 \mathrm{~dB}$ intensity) with an aversive unconditioned stimulus (US) (a 1.5
$\mathrm{mA}$ footshock). Mice were handled for $2 \mathrm{~min}$ in the conditioning room on each of 3 consecutive days before training. During training, mice were placed in the conditioning chamber for $3 \mathrm{~min}$. After $2 \mathrm{~min}$ in the chamber, mice received a single CS-US pairing consisting of $30 \mathrm{~s}$ of white noise, coterminating with a $2 \mathrm{~s}$ footshock. Either $24 \mathrm{~h}$ (long-term test) or $1 \mathrm{~h}$ (short-term test) later, mice were returned to the same chamber for 5 min. One hour after testing in the original context, the animals were tested in a novel context, a separate chamber lacking a grid floor and with differing spatial, visual, and olfactory cues. After $2 \mathrm{~min}$ in the new chamber, mice were reexposed to the CS for $3 \mathrm{~min}$. An observer blind to genotype manually assessed freezing behavior, defined as complete lack of movement except for respiration, in intervals of $5 \mathrm{~s}$ throughout training and testing trials. Groups of four mice were trained and tested simultaneously in four separate conditioning chambers. Each chamber was cleaned between animals with $75 \%$ ethanol during training and contextual testing or with dilute lemon-scented detergent during cued testing. To test shock sensitivity, mice were placed in a conditioning chamber for $2 \mathrm{~min}$ and given a series of footshocks of increasing intensity from 0.05 to $1.0 \mathrm{~mA}$ in $0.05 \mathrm{~mA}$ increments. Each shock was separated by $10 \mathrm{~s}$. This procedure was repeated once, and results were averaged. Videotapes were scored for flinching (any noticeable reaction), vocalizing (any audible response), and jumping (at least two paws leaving the grid floor) during delivery of the shock. Different groups of mice were used in tests of long-term conditioning, short-term conditioning, and shock sensitivity.

Elevated zero maze. Activity and anxiety-related behavior were measured in the elevated zero maze test as described previously (Ecker et al., 2004). A circular variant of the elevated plus maze, the zero maze apparatus consists of a raised circular track divided into two open and two closed quadrants. The track had an internal diameter of $40.5 \mathrm{~cm}$ and a width of $5.1 \mathrm{~cm}$ and was elevated off the floor at a height of $40 \mathrm{~cm}$. The closed quadrants had walls $11 \mathrm{~cm}$ high. Mice were housed individually for $1 \mathrm{~h}$ before testing and then placed into the center of a closed quadrant and observed for $5 \mathrm{~min}$. Digitized video of each $5 \mathrm{~min}$ trial was scored manually and also analyzed using automated behavioral analysis software (Clever Systems, Reston, VA) to determine the percentage of time, total distance, and average speed of the animals in open and closed quadrants, the number of transitions between quadrants, the number of episodes of stretch-attend posture (SAP), and the number of head dips.

Light-dark exploration. Anxiety-related behavior was tested in the light-dark exploratory activity test as described previously (Miyakawa et al., 2001). The testing apparatus was a large plastic rodent cage $(45.5 \times$ $25.6 \times 15.3 \mathrm{~cm}$ ) modified so that two-thirds of the cage was open and brightly lit and the remaining one third was dark and enclosed. Passage between the light and dark compartments was possible via a small opening $7.5 \mathrm{~cm}$ wide and $5 \mathrm{~cm}$ high. Each mouse was placed in the center of the open compartment facing away from the dark compartment and videotaped for $10 \mathrm{~min}$. Videotapes were scored manually to determine the latency to enter the dark compartment, the percentage of time in the open compartment, and the number of transitions between compartments.

Open field. Baseline locomotor activity was measured as described by Qin et al. (2002) in a $41 \times 41 \mathrm{~cm}$ square arena equipped with a $16 \times 16$ grid of photobeam sensors spaced $2.54 \mathrm{~cm}$ apart (San Diego Instruments, San Diego, CA). A second array of 16 photobeam sensors at a height of 5 $\mathrm{cm}$ measured vertical activity such as rearing and jumping. Each mouse was placed in the center of the arena, and beam breaks were recorded in $1 \mathrm{~min}$ intervals over either 15 or $30 \mathrm{~min}$. Activity levels were observed to plateau by $15 \mathrm{~min}$, so all data were combined and only the first $15 \mathrm{~min}$ were analyzed. Light intensity in the square arena was 165 lux in the center and averaged 144 lux in the corners. Mice tend to keep to the walls of the open-field arena, and the percentage of beam breaks occurring in the center of the open area is commonly used as a measure of anxietyrelated behavior (Simon et al., 1994). The center area was defined as the centermost 12 photobeams in each direction.

Acoustic startle responses and prepulse inhibition. Whole-body acoustic startle responses and PPI of the startle response were measured using the SR-Lab System (San Diego Instruments) as described previously (Gould et al., 2004). Testing was conducted in $35 \times 33 \times 38.5 \mathrm{~cm}$ soundattenuating chambers, each ventilated with a small fan and illuminated 
by a $15 \mathrm{~W}$ light bulb mounted in the ceiling. Mice were placed in clear Plexiglas cylinders $(16 \times 8.75 \mathrm{~cm})$ mounted on Plexiglas frames $(12.5 \times$ $20.5 \times 0.6 \mathrm{~cm}$ ) elevated $2.75 \mathrm{~cm}$ above a $30 \times 30 \times 4 \mathrm{~cm}$ base by screws positioned at each corner. Acoustic stimuli were delivered through a speaker mounted in the ceiling of each chamber, $23 \mathrm{~cm}$ above the cylinders, and startle responses were detected by piezoelectric accelerometers mounted beneath each frame. Output signals were digitized, rectified, and recorded as consecutive $1 \mathrm{~ms}$ readings using San Diego Instruments Startle Reflex software. The average startle response and maximum amplitude of the startle response were recorded as San Diego Instruments startle units. Both startle responses and PPI were measured during a single session, and results from three such sessions conducted on 3 consecutive days were averaged for each mouse. Sessions started with a $5 \mathrm{~min}$ acclimation period of $65 \mathrm{~dB}$ background noise, followed by five $120 \mathrm{~dB}$ startle pulses. Startle trials used $40 \mathrm{~ms}$ pulses at 0 (no stimulus), 90, 95, $100,105,110,115$, and $120 \mathrm{~dB}$. After startle testing, PPI was measured for prepulse intensities of 72,76, and $84 \mathrm{~dB}$ or no stimulus. Each prepulse lasted $20 \mathrm{~ms}$ and was followed $100 \mathrm{~ms}$ later by a $40 \mathrm{~ms}$ startle stimulus at $120 \mathrm{~dB}$. All startle and prepulse trials were administered five times each in a random order, with intertrial intervals randomized to $10-20 \mathrm{~s}$. Data were collected as 601 -ms voltage readings, which were averaged over the collection interval to give an average startle measure for each trial. Percentage of PPI for each prepulse intensity was calculated as $100-100 \times$ (startle with prepulse/startle without prepulse).

HPLC. Levels of monoamine neurotransmitters were determined using HPLC essentially as described previously (Robinson et al., 1992). translin $\mathrm{KO}$ and WT mice of the same sex were killed and dissected in random order. After cervical dislocation, brains were removed from translin KO mice and WT littermates and rinsed briefly in cold PBS. Samples of the amygdala, hippocampus, cortex, prefrontal cortex (PFC), and striatum were rapidly dissected on ice, frozen in Eppendorf (Westbury, NY) tubes submerged in liquid nitrogen, and stored at $-80^{\circ} \mathrm{C}$. Samples were coded so that those performing the neurochemical analyses were blinded to the genotype. Each sample was diluted 1:10 directly into homogenizing buffer containing 3,4-dihydroxybenzylamine as an internal standard. Samples were sonicated on ice for $10 \mathrm{~s}$ and centrifuged at $14,000 \mathrm{rpm}$ at $0^{\circ} \mathrm{C}$ for $20 \mathrm{~min}$; HPLC analyses were generally performed on the same day. Approximately $30 \mu \mathrm{l}$ of tissue sample was combined with $2.5 \mu \mathrm{l}$ of ascorbate oxidase. Samples were injected onto a C18 reverse-phase column (ODS, $150 \times 4.6 \mathrm{~mm} ; 5 \mu \mathrm{m}$ particles; Thermo Electron Corporation, Waltham, MA) by a Waters (Milford, MA) 717 Plus Autosampler, eluted using an isocratic system with a mobile phase (MD-TM; ESA, Bedford, MA), and pumped by a Waters 515 HPLC pump. Under these conditions, norepinephrine (NE), serotonin (5-HT), 5-hydroxyindole-3-acetic acid (5-HIAA), dopamine (DA), 3,4dihydroxyphenylacetic acid (DOPAC), and homovanillic acid (HVA) can easily be resolved. The norepinephrine metabolite 3-methoxy-4hydroxylphenylglycol (MHPG) elutes very near the injection front and was measured separately. External standards ranging from 0 to $10 \mathrm{pmol}$ were injected every fifth specimen. The $10 \mathrm{pmol}$ standard was injected twice (first and last) to determine whether there had been any drift during the analysis. A Coulochem II electrochemical detector equipped with a 5011 analytical cell (ESA) was used to detect the biogenic amines. Data were captured using the Empower Software system (Waters).

Order of testing. No mouse was exposed to either fear conditioning or shock threshold testing procedures more than once, and these tests were the last to be performed on any group of animals. Before fear conditioning or shock threshold testing, some mice were tested in the elevated zero maze or the light-dark box, the open-field test, the Morris water maze, or acoustic startle and prepulse inhibition in that sequence. Mice used for neurochemical measurements were entirely naive and were not subjected to any behavioral testing.

Statistical analysis. Data derived from water maze training trials, fear conditioning, open-field testing, acoustic startle testing, and prepulse inhibition were analyzed using three-way repeated-measures ANOVA with genotype, sex, and training day, testing condition, minute, acoustic stimulus intensity, or prepulse intensity as factors. Significant differences identified by ANOVA were further investigated using Tukey-Kramer post hoc multiple comparison procedures to account for different num- bers of animals in each group. Data from the zero maze and the lightdark exploration test were analyzed using two-way ANOVA with genotype and sex as factors. When data initially failed tests of normality or equal variance, typically because of floor effects, nonparametric analyses were used. Cox proportional hazards regression models were used to compare the time to find the platform in the water maze between WT and KO mice over training days, stratified by sex and condition (acquisition, reversal, and visible). In this analysis, the hazard ratio represents the relative risk of finding the platform during a given period. The $z$-value is the ratio of each calculated regression coefficient to its SE. Interactions between day of trial and genotype were also tested. These models were adjusted for clustering by mouse across repeated measures using the robust variance estimator (Lin and Wei, 1989). Because many mice showed no thigmotaxis or no jumping behavior, logistic regression was used to compare the odds of any thigmotaxis versus no thigmotaxis and jumps versus no jumps between genotypes and over time, stratified by sex and condition. Generalized estimating equations methodology was used to adjust for clustering by mouse attributable to repeated measures over training days (Zeger and Liang, 1986). Again, interactions between day of trial and genotype were also tested. In several cases in which no jumps were recorded for WT mice, Fisher's exact test was used in place of the $\chi^{2}$ test for calculating $p$ values. All data are expressed as the group mean or percentage, with error bars signifying the SEM or percentage.

\section{Results}

\section{Male translin KO mice exhibit performance deficits in the water maze but are able to learn the position of the hidden platform}

To determine whether translin is required for spatial learning and memory in mice, we tested translin KO mice and WT littermates in the hippocampus-dependent, hidden platform version of the Morris water maze. After acquisition of the initial hidden platform position, reversal training was performed to assess the flexibility of spatial memory, and visible training was performed to detect deficits in nonspatial components of the task, such as motor and sensory ability, attention, or motivation. We trained translin KO mice ( $n=13,7$ males and 6 females) and WT littermates ( $n=16,9$ males and 8 females) to find the hidden platform using four trials per day over $6 \mathrm{~d}$, followed by $3 \mathrm{~d}$ of reversal training and $4 \mathrm{~d}$ of training with the visible platform. Male and female mice of both genotypes significantly improved their performance across training days during acquisition $(z=7.80, p<$ 0.001 for males and $z=8.03, p<0.001$ for females for day 6 vs day 1); however, male translin $\mathrm{KO}$ mice exhibited significantly longer escape latencies than WT littermates overall (Fig. 1A) $(z=$ $2.82 ; p<0.01)$. Female translin $\mathrm{KO}$ mice exhibited somewhat longer relative latencies during the first $2 \mathrm{~d}$ of acquisition training, but this difference was not significant and disappeared over the remaining trials (Fig. $1 B)(z=1.24 ; p=0.22)$. translin $\mathrm{KO}$ mice and WT littermates of both sexes showed significant improvements in performance across trials during reversal testing $(z=6.71, p<0.001$ for males and $z=7.52, p<0.001$ for females for day 3 vs day 1); however, male translin $\mathrm{KO}$ mice again exhibited longer escape latencies overall (Fig. $1 A)(z=2.08 ; p<0.05)$, primarily because of poor performance on the third day of reversal training. In visible training, males and females of both genotypes again improved their performance over training days $(z=$ 3.37, $p<0.001$ for males and $z=6.80, p<0.001$ for females for day 4 vs day 1 ). The performance of female mice did not differ significantly by genotype, but there was a main effect of genotype (Fig. 1A) $(z=3.84 ; p<0.001)$ and a significant interaction between genotype and training day $\left(\chi^{2}\right.$ test, $\left.p<0.05\right)$ for male mice. Male translin $\mathrm{KO}$ mice exhibited significantly longer escape latencies than male WT littermates on each of the last $3 \mathrm{~d}$ of 

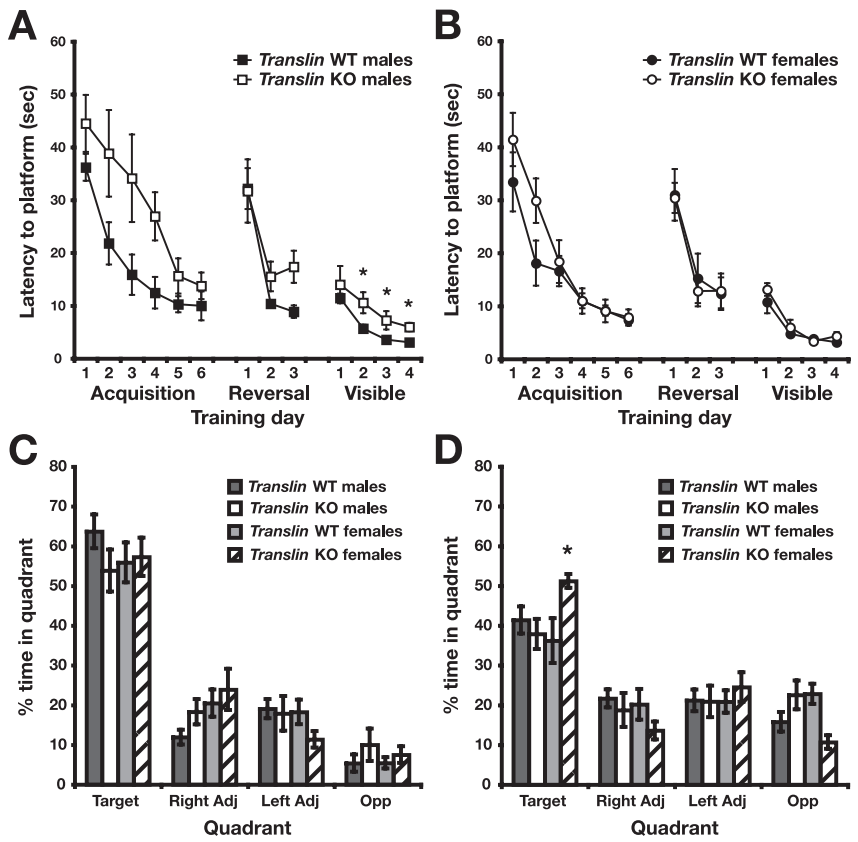

Figure 1. Male translin K0 mice exhibit increased escape latencies during training in the Morris water maze, but spatial memory as assessed by probe trials is not impaired. translin KO mice ( $n=13,7$ males and 6 females) and WT littermates ( $n=17,9$ males and 8 females) were placed in a pool of water made opaque with white paint and trained using four trials per day over multiple days to find a submerged platform at an initial location (Acquisition; days 1-6), at a new location on the opposite side of the pool (Reversal; days 1-3), and at varying locations identified with a visible marker extending from the surface of the pool (Visible; days 1-4). Probe trials in which the platform was removed and mice were allowed to search the pool for $60 \mathrm{~s}$ were performed after acquisition and reversal training. $A$, Male translin $\mathrm{K} 0$ mice exhibited significantly longer escape latencies than WT littermate controls during acquisition, reversal, and visible platform training. $\boldsymbol{B}$, Escape latency did not differ significantly between female translin KO mice and WT controls. C, After $6 \mathrm{~d}$ of training with the platform in its initial location, translin KO mice and WT littermate controls of both sexes spent a significantly greater percentage of time in the quadrant that previously contained the hidden platform (target) relative to the other quadrants. $\boldsymbol{D}$, After $3 \mathrm{~d}$ of training with the platform in a new location, all groups showed a significant preference for the new target quadrant. Female translin KO mice spent a significantly greater percentage of time in the target quadrant than male KO mice and WT controls. ${ }^{*} p<0.05$. Opp, Opposite; Adj, Adjacent.

visible platform training (Fig. $1 A)(z=2.78,2.87$, and 3.84; $p<$ 0.05 for each day).

Male translin $\mathrm{KO}$ mice took longer to find the hidden platform during acquisition training, but their performance approached that of WT mice by the fifth and sixth days of training. Indeed, both translin KO mice and WT controls of both sexes showed a significant preference for the quadrant that previously contained the hidden platform in a probe trial performed on day 7 (Fig. 1C) $\left(F_{(3,78)}=113.616 ; p<0.0001\right)$, indicating that all groups were able to learn the platform position. A probe test was also performed after reversal training (Fig. 1D). Despite the poor performance of male $\mathrm{KO}$ mice on day 3 , all groups showed a significant preference for the new target quadrant $\left(F_{(3,78)}=32.469 ; p<\right.$ 0.001 ). Surprisingly, female translin $\mathrm{KO}$ mice actually showed a greater preference for the new target quadrant than female WT mice or males of either genotype (quadrant $\times$ genotype $\times$ sex interaction, $F_{(3,78)}=4.365, p<0.01$; Tukey-Kramer test, $p<$ 0.05 for target quadrant).

The small but significant increase in escape latency in male translin KOs relative to WT littermates in the visible platform test indicates that there is a fundamental impairment in performance independent of differences in spatial learning. Deficits in motor
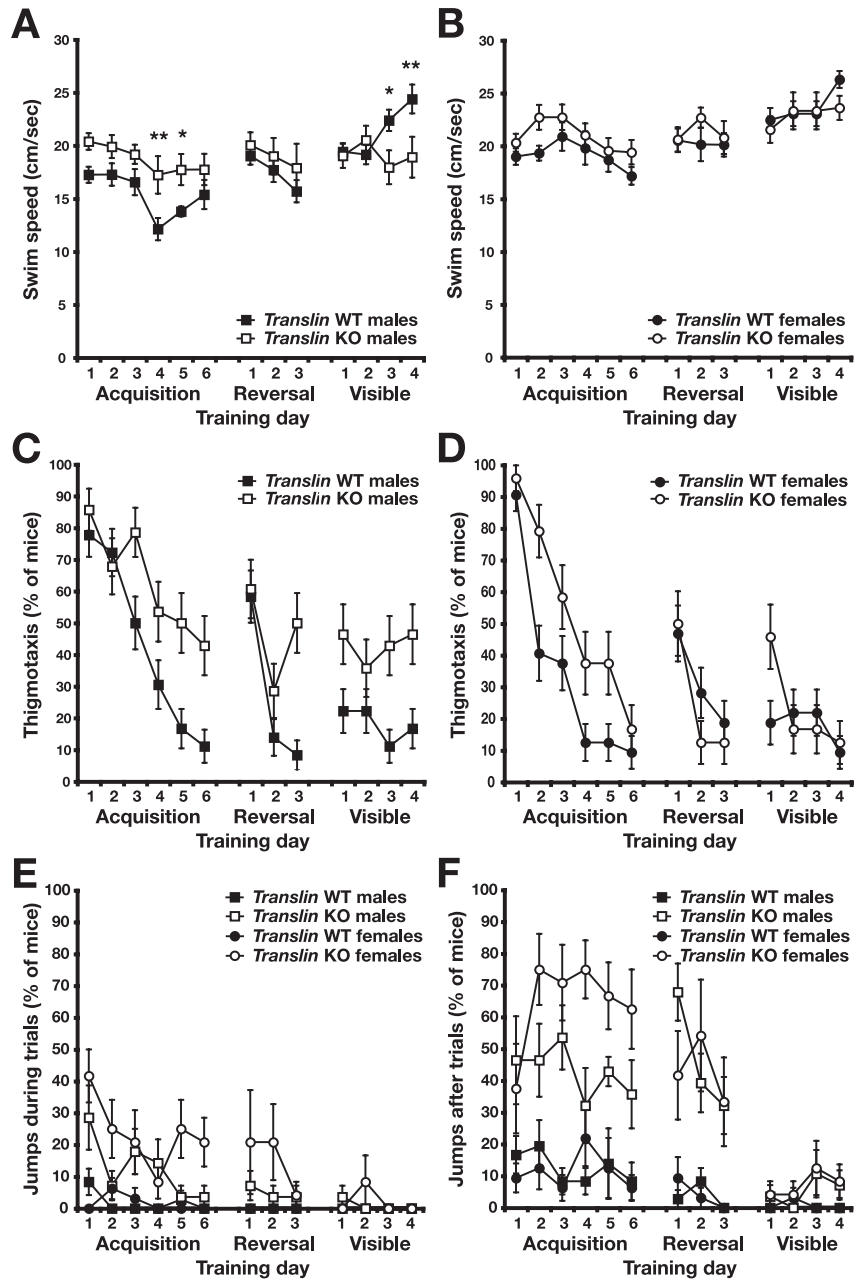

Figure 2. Increased escape latency in translin $\mathrm{KO}$ mice in the Morris water maze may be related to differences in swim speed, thigmotaxis, or jumping behavior. Swim speed, thigmotaxis, and jumping behavior of translin $\mathrm{KO}$ mice ( $n=13,7$ males and 6 females) and WT littermates ( $n=17,9$ males and 8 females) were recorded throughout acquisition, reversal, and visible platform training in the Morris water maze. $\boldsymbol{A}$, Relative to male WT controls, the average swim speed of male translin $\mathrm{K} 0$ mice was significantly greater during hidden platform training and slower during visible platform training. $\boldsymbol{B}$, Although there was a significant difference in average speed between female translin K0 mice and WT littermates overall, post hoc tests did not reveal significant differences on any given day. C, Swimming around the periphery of the pool, a behavior termed thigmotaxis, occurred in a significantly higher proportion of male translin $\mathrm{KO}$ mice than male WT littermates at the end of acquisition and during visible platform training. D, Female translin $\mathrm{KO}$ mice also exhibited significantly more thigmotaxis during acquisition but not during reversal or visible platform training. $\boldsymbol{E}, \boldsymbol{F}$, After locating the hidden platform during a given trial, mice are allowed to sit on it for $20 \mathrm{~s}$ before being returned to the home cage, but they occasionally jump back into the pool after finding the platform. translin KO mice of both sexes exhibited more of this jumping behavior than WT littermates immediately after finding the platform during acquisition and reversal training $(\boldsymbol{E})$ and when we attempted to retrieve them from the platform throughout training $(\boldsymbol{F}) .{ }^{*} p<0.05 ;{ }^{* *} p<0.01$.

function could possibly limit the minimum escape latency achieved by male $\mathrm{KO}$ mice during training; however, male $\mathrm{KO}$ mice exhibited significantly higher swim speeds than male WT littermates during acquisition (Fig. 2A) (genotype $\times$ trial, $F_{(14,196)}=9.561, p<0.001 ;$ day $4, p<0.01$; day $\left.5, p<0.05\right)$, suggesting that motor ability is not impaired. Conversely, male KO mice exhibited slower average speeds than male WT mice in swimming to the visible platform (visible day $3, p<0.05$; day 4 , $p<0.01$ ). For females, there was also a significant interaction between trial and genotype, indicating higher swim speed in female KO mice overall (Fig. $2 B)\left(F_{(14,168)}=1.805 ; p<0.05\right)$, but 
post hoc testing did not reveal significant differences on any particular training day.

Several additional observations suggest alternative explanations for impaired escape behavior in translin $\mathrm{KO}$ mice. When first introduced to the water maze, most mice swim around the edge of the pool, a behavior called thigmotaxis. Much of the initial improvement in escape latency during acquisition training comes as the mice adopt a different search strategy and swim into the center of the pool (Schenk and Morris, 1985), and differences in thigmotaxis can account for significant behavioral variability between mutant and WT mice in the water maze (Wolfer et al., 1998). Male translin KO mice exhibited persistent thigmotaxis relative to WT controls that may have interfered with performance (genotype $\times$ day, $p<0.01$; genotype on day $6, p<0.01$ ). Persistent thigmotaxis may also explain the relatively higher swim speed of male $\mathrm{KO}$ mice during acquisition. Starting on day 4 , there is a relative reduction and a subsequent recovery in swim speed in male WT mice that may reflect a progression from thigmotaxis to slower active searching to memory for the platform position. Male translin $\mathrm{KO}$ mice continued to show higher overall levels of thigmotaxis during reversal and visible platform training (main effects of genotype, $p<0.05$ and $p<0.001$, respectively). In females, the amount of thigmotaxis also decreased during acquisition training in both groups (Fig. 2D) (main effect of day, $p<0.0001$ ) but was higher overall in translin $\mathrm{KO}$ mice (main effect of genotype, $p<0.0001$ ). Thigmotaxis did not differ according to genotype during reversal or visible platform training in female mice.

Because most mice do not find the platform during early trials, initial improvements in water maze performance also require that mice cooperate in being guided to the platform. In training translin $\mathrm{KO}$ mice and their WT littermates, we noticed that many of the mice swam away rapidly and refused to be guided to the platform. Furthermore, on reaching the platform or being guided to it, mice would frequently jump off and continue swimming. During acquisition and reversal, this behavior occurred significantly more frequently in male and female translin $\mathrm{KO}$ mice (Fig. $2 E$ ) (acquisition, $\chi^{2}$ test, $p<0.0001$ for males and $p<0.05$ for females; reversal, Fisher's test, $p<0.05$ for males and $p<0.0001$ for females). Throughout testing phases, male and female translin KO mice also displayed a significant tendency to jump off the platform when we attempted to return them to the home cage (Fig. $2 F$ ) (acquisition, $\chi^{2}$ test, $p<0.001$ for males, $p<0.0001$ for females; reversal, $\chi^{2}$ test $p<0.0001$ for males, $p<0.01$ for females; visible, Fisher's test, $p<0.01$ for males, $p<0.05$ for females). We previously observed the latter type of behavior, excessive jumping and running apparently in response to the threat of capture, when attempting to remove translin $\mathrm{KO}$ mice from their home cages. Interestingly, we also observed multiple episodes of tonic-clonic seizures in both male and female translin $\mathrm{KO}$ mice that seem to be provoked by such routine handling. Seizures were not observed during behavioral testing or in WT littermates.

\section{Female translin KO mice exhibit enhanced conditioned freezing}

To further assess learning and memory, we tested translin $\mathrm{KO}$ mice and WT littermates in cued and contextual fear conditioning. This task has the advantage that learning occurs in a single trial and that cued and contextual conditioning can dissociate dysfunction in different brain areas. Both types of learning require the amygdala, but contextual conditioning also depends on the hippocampus (Phillips and LeDoux, 1992). translin KO mice
( $n=23,13$ males and 10 females) and WT littermates $(n=23,12$ males and 11 females) were conditioned to the shock context and the auditory cue and tested $24 \mathrm{~h}$ later. Conditioning had a significant effect on freezing responses (Fig. $3 A)\left(F_{(5,210)}=122.388\right.$; $p<0.001)$. Mice exhibited significantly increased freezing relative to baseline when reexposed to the context in which they received the shock $24 \mathrm{~h}$ after training $(p<0.001)$, indicating memory for the context. Both groups also demonstrated a small but significant increase in freezing when placed in a new context $24 \mathrm{~h}$ after training $(p<0.01)$, suggesting some degree of generalization of the US, and an additional significant increase in freezing in the new context during the period when the auditory stimulus was played $(p<0.001)$. There was also a main effect of genotype on the level of freezing responses $\left(F_{(1,210)}=7.966 ; p<\right.$ $0.01)$, as well as a conditioning $\times$ genotype $X$ sex interaction $\left(F_{(5,210)}=2.434 ; p<0.05\right)$. Freezing levels did not differ at baseline in either context, but female translin $\mathrm{KO}$ mice showed significantly enhanced freezing relative to WT littermates when reexposed to either the context in which they received the shock or the auditory stimulus that accompanied the shock $(p<0.05, p<$ 0.01 , respectively). In contrast, male translin $\mathrm{KO}$ mice did not exhibit enhanced freezing at $24 \mathrm{~h}$ but did exhibit significantly increased freezing during the $30 \mathrm{~s}$ period immediately after the shock on the training day $(p<0.05)$.

To assess short-term memory for contextual and cued conditioning, we trained a second cohort of translin KO mice $(n=18$, 5 males and 13 females) and WT littermates $(n=31,17$ males and 14 females) using the same conditioning protocol, but this time we reexposed the mice to the context $1 \mathrm{~h}$ after training and the auditory cue in a new context $2 \mathrm{~h}$ after training. All groups again showed significantly increased freezing during contextual and cued testing (Fig. 3B) $\left(F_{(1,225)}=135.264 ; p<0.0001\right)$. There were significant interactions between conditioning and genotype $\left(F_{(5,225)}=2.335 ; p<0.05\right)$ and conditioning and $\operatorname{sex}\left(F_{(5,225)}=\right.$ $2.642 ; p<0.05)$. Female translin $\mathrm{KO}$ mice again demonstrated significantly enhanced freezing responses relative to WT littermates during cued testing in the novel context $(p<0.01)$, but the level of freezing during reexposure to the original context did not differ significantly for male or female mice. The level of freezing immediately after conditioning was not significantly higher in male translin $\mathrm{KO}$ mice in this experiment; however, combining data from the training day for both cohorts revealed a main effect of genotype $\left(F_{(1,182)}=7.400 ; p<0.01\right)$, as well as interactions between conditioning and genotype $\left(F_{(2,182)}=8.038 ; p<0.001\right)$ and conditioning and $\operatorname{sex}\left(F_{(2,182)}=5.836 ; p<0.01\right)$. Using data from both experiments, freezing behavior immediately after conditioning was significantly increased for male translin $\mathrm{KO}$ mice relative to WT littermates $(p<0.01)$.

Footshocks administered repeatedly or at higher current levels produce more robust freezing responses in rodents (Baldi et al., 2004). To test whether enhanced freezing in translin KO mice might be related to differences in shock sensitivity, we exposed a separate group of translin $\mathrm{KO}$ mice ( $n=14,8$ males and $6 \mathrm{fe-}$ males) and WT littermates ( $n=17,8$ males and 9 females) to a series of shocks of increasing intensity and determined the amount of current required to elicit various reactions from the mice. The average current thresholds required to produce flinching, vocalizing, and jumping behavior were not significantly different between translin KO mice and WT littermates (Fig. 3C), indicating that differences in shock sensitivity do not account for the enhanced freezing observed in the KO mice. 

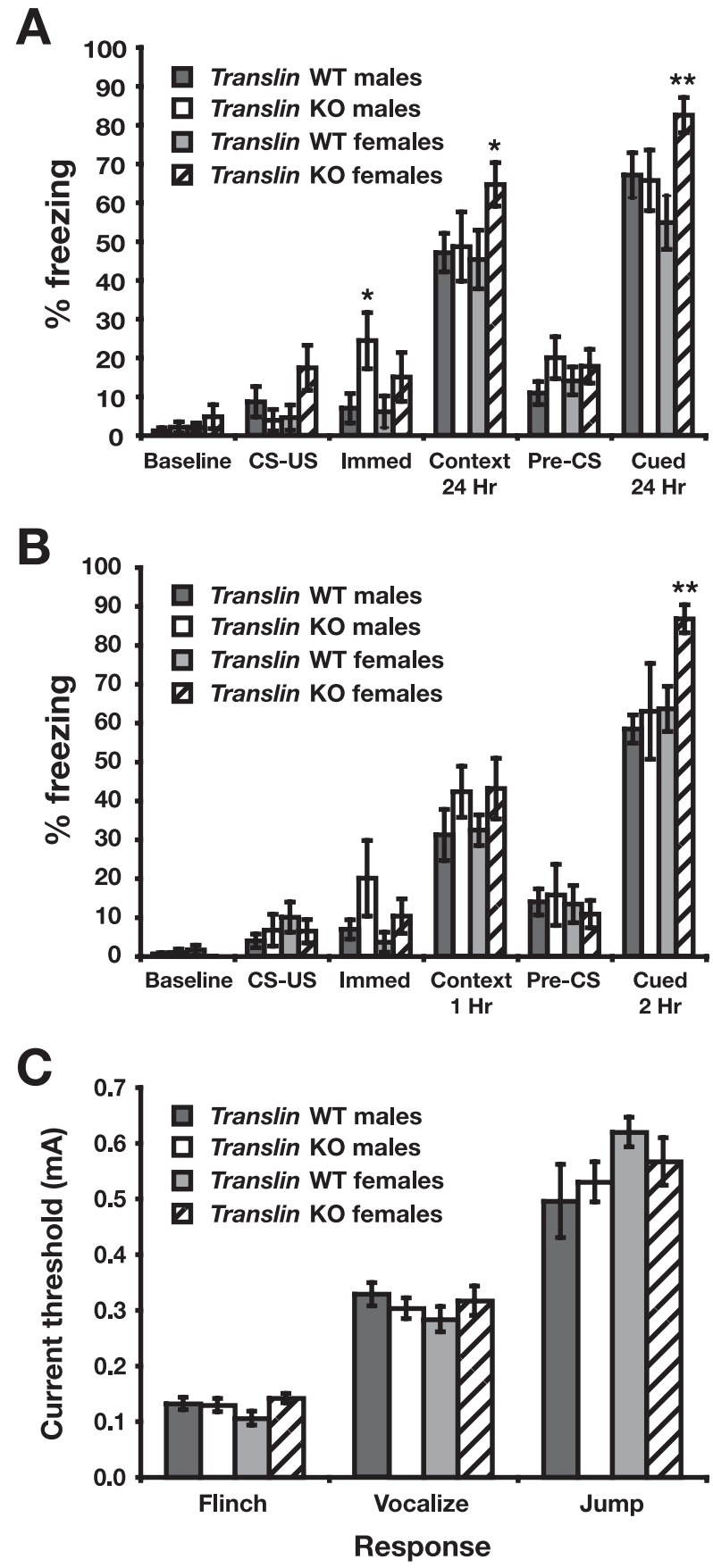

Figure 3. Female translin KO mice exhibit significantly enhanced freezing after contextual and cued fear conditioning. translin KO mice ( $n=23,13$ males and 10 females) and WT littermates ( $n=23,12$ males and 11 females) were placed in conditioning chambers in which they received an auditory $\mathrm{CS}$ ( $30 \mathrm{~s}$ of $85 \mathrm{~dB}$ white noise) coterminating with an US ( $2 \mathrm{~s}, 1.5 \mathrm{~mA}$ footshock). Freezing behavior was assessed in the chamber before conditioning (Baseline; 2 $\mathrm{min}$ ), during the period of $(\mathrm{S}$ and US presentation (CS-US; $30 \mathrm{~S}$ ), immediately after conditioning (Immed; $30 \mathrm{~s}$ ), $24 \mathrm{~h}$ later in the same chamber (Context; $5 \mathrm{~min}$ ), and in a new chamber representing a different context both before (Pre- $\mathrm{CS} ; 2 \mathrm{~min}$ ) and during (Cued; $3 \mathrm{~min}$ ) $\mathrm{CS}$ presentation. $A$, All groups exhibited significant freezing responses relative to baseline when reexposed to the context or the CS24 h after conditioning, but female translin K0 mice showed significantly more freezing than female WT mice and males of either genotype. Male translin KO mice demonstrated significantly enhanced freezing immediately after training. $\boldsymbol{B}$, In a separate experiment with a new group of translin KO mice ( $n=18,5$ males and 13 females) and WT littermates ( $n=31,17$ males and 14 females), female translin K0 mice also exhibited enhanced freezing during presentation of the $\mathrm{CS} 2 \mathrm{~h}$ after conditioning. C, Shock sensitivity, as assessed by the average current level required to produce flinching, vocalizations, or jumping behavior, did not differ significantly between translin KO mice ( $n=14,8$ males and 6 females) and WT littermates $\left(n=17,8\right.$ males and 9 females). ${ }^{*} p<0.05 ;{ }^{* *} p<0.01$.
Male and female translin $\mathrm{KO}$ mice exhibit reduced anxiety-related behavior

Given their enhanced freezing after fear conditioning and jumping behavior during water maze training, we hypothesized that translin $\mathrm{KO}$ mice might also exhibit altered unconditioned responses in tests of anxiety-related behavior. Anxiety-related behavior is reduced in fmrl KO mice (Bakker et al., 1994; Peier et al., 2000; Qin et al., 2002; Mineur et al., 2002) and increased in mice lacking the untranslated dendritic RNA BC1 (Lewejohann et al., 2004). We used two related behavioral paradigms, the elevated zero maze test and the light-dark exploration test, to assess anxiety-related behavior in translin $\mathrm{KO}$ mice and WT littermates. In both tests, the source of anxiety is thought to be a conflict between the innate tendencies of rodents to explore novel environments while avoiding unfamiliar, exposed areas where they could be subject to predators (Treit et al., 1993a). Mice that spend more time in the open are considered less anxious, an interpretation supported by the finding that treatment with anxiolytic drugs increases time spent in open areas in both tests (Onaivi and Martin, 1989; Shepherd et al., 1994).

In the zero maze, translin $\mathrm{KO}$ mice $(n=22,13$ males and 9 females) and WT littermates ( $n=22,14$ males and 8 females) were placed in the center of a closed quadrant and observed for 5 $\mathrm{min}$. Both male and female $\mathrm{KO}$ mice spent a significantly greater percentage of time in the open quadrants than their WT littermates (Fig. $4 A)\left(F_{(1,40)}=23.433, p<0.0001\right.$; males, $p<0.01$; females, $p<0.001$ ), indicating a reduction in anxiety-related behavior that was supported by several additional measurements. Mice often investigate the open quadrant with their nose and forepaws while keeping their hindquarters protected in the closed quadrant. The number of such entries into the open quadrants did not differ significantly between groups, but male translin $\mathrm{KO}$ mice ventured completely into the open quadrants significantly more often than WT controls (Fig. $4 B$ ) (main effect of genotype, $F_{(1,40)}=5.818, p<0.05$; males, $p<0.05$; females, $\left.p=0.24\right)$. Although the total distance traveled in the closed quadrants of the zero maze did not differ between genotypes, both male and female translin $\mathrm{KO}$ mice traveled significantly farther in the open quadrants of the maze (Fig. $4 C)\left(F_{(1,40)}=25.835, p<0.00001\right.$; males, $p<0.001$; females, $p<0.01$ ). Average speed in both closed and open quadrants was significantly higher in translin $\mathrm{KO}$ mice compared with WT mice, primarily because of differences among male mice (Fig. $4 D$ ) (closed: genotype, $F_{(1,40)}=6.63, p<0.05$; genotype $\times \operatorname{sex}, F_{(1,40)}=2.55, p=0.12$; males, $p<0.01$; females, $p=0.54$; open: genotype, $F_{(1,40)}=7.55, p<0.01$; genotype $\times$ sex, $F_{(1,40)}=3.70, p=0.06$; males, $p<0.001$; females, $p=0.60$ ). This increase in average speed, particularly in closed quadrants, suggests a fundamental increase in locomotor activity in male translin $\mathrm{KO}$ mice. To separate anxiety from activity, we counted episodes of SAP and head dips, two ethological measures of anxiety-related behavior that are sensitive to pharmacological modulation (Shepherd et al., 1994). Male and female translin KO mice exhibited significantly fewer anxious SAPs than WT littermates (Fig. $4 E$ ) (data failed normality for males, rank-sum test, $p<0.01 ; t$ test, $p<0.05$ for females). translin $\mathrm{KO}$ mice also showed significantly more exploratory head dips than WT littermates (Fig. $4 F)\left(F_{(1,40)}=6.95 ; p<0.05\right)$. The difference was significant for male KO mice $(p<0.05)$ but did not reach significance for females $(p=0.17)$, probably because of the smaller group size. Overall, female mice exhibited significantly fewer head dips than male mice $\left(30.0 \pm 2.7\right.$ vs $40.0 \pm 2.9 ; F_{(1,40)}=$ $5.834 ; p<0.05)$. There was not a main effect of sex in any of the other measures of zero maze performance. 

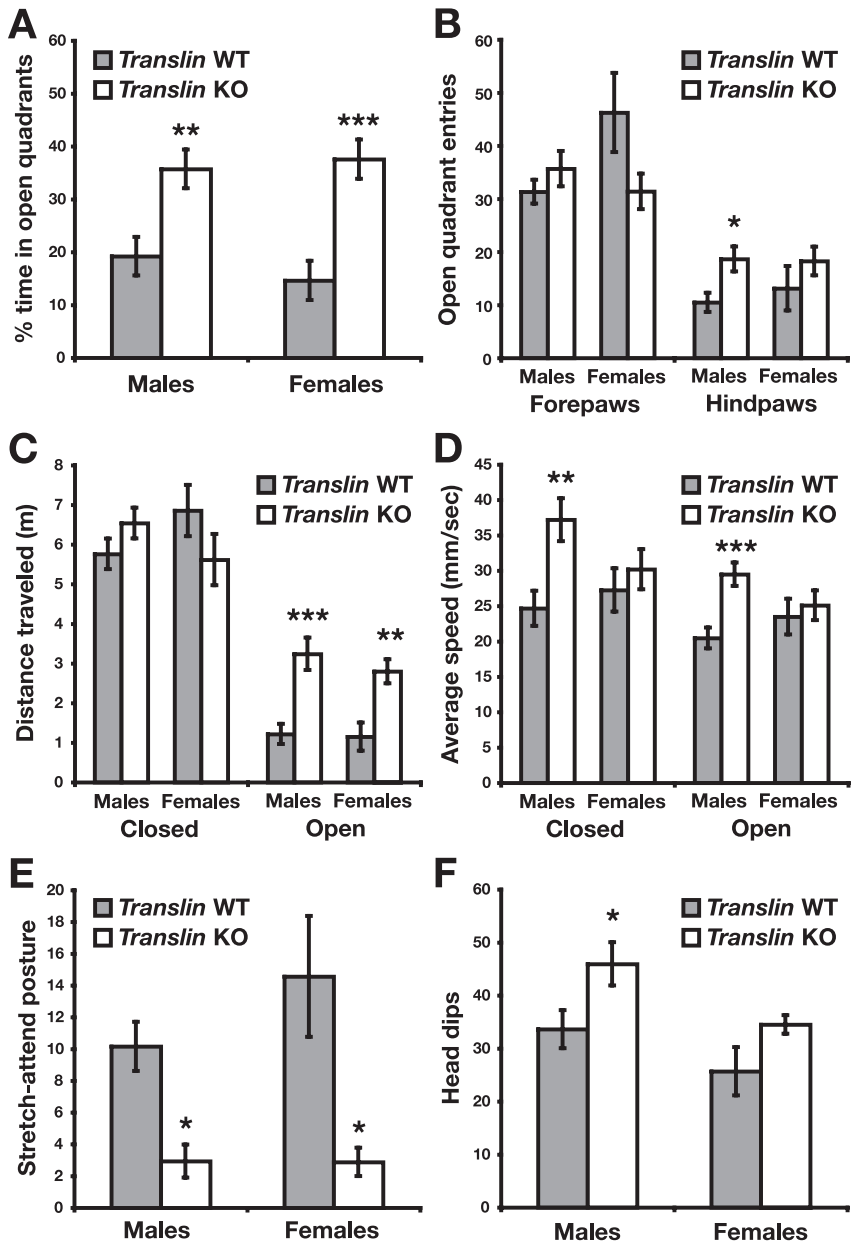

Figure 4. translin $\mathrm{KO}$ mice exhibit reduced anxiety-related behavior in the elevated zero maze test. translin K0 mice ( $n=22,13$ males and 9 females) and WT littermates ( $n=22,14$ males and 8 females) were placed in the center of a closed quadrant of the elevated zero maze and observed for $5 \mathrm{~min}$. $A$, Both male and female translin $\mathrm{KO}$ mice spent a significantly greater percentage of time in the open quadrants of the zero maze than WT littermates. $\boldsymbol{B}$, The number of entries into the open quadrants with the head or forepaws did not differ significantly between genotypes, but, of these entries, male translin $\mathrm{KO}$ mice ventured completely into the open significantly more often. $C$, Both male and female translin K0 mice traveled significantly farther in the open but not the closed quadrants of the zero maze. $D$, The average speed of male translin KO mice was significantly greater than WT controls in both the open and closed quadrants. $\boldsymbol{E}$, Episodes of stretch-attend posture, a stereotyped behavior in which mice tentatively sample the environment by extending their snout and forepaws while keeping their hindpaws in place, were significantly reduced in translin $\mathrm{KO}$ mice. $\boldsymbol{F}$, The number of head dips, an exploratory behavior in which mice extend their snout past the inside or outside edge of the open quadrants, was significantly greater in male mice overall and in male translin $\mathrm{KO}$ mice relative to male WT littermates. ${ }^{*} p<0.05 ;{ }^{* *} p<0.01 ;{ }^{* * *} p<0.001$.

We tested a separate group of translin $\mathrm{KO}$ mice $(n=15,9$ males and 6 females) and WT littermates $(n=20,14$ males and 6 females) in the light-dark exploration test. In this case, there was a main effect of sex on the behavior of the mice; females spent more time in the dark compartment $\left(F_{(1,31)}=8.701 ; p<0.01\right)$ and made fewer transitions between compartments $\left(F_{(1,31)}=\right.$ 5.721; $p<0.05)$. Accounting for sex differences, translin $\mathrm{KO}$ mice spent a significantly greater percentage of time in the light compartment over the $10 \mathrm{~min}$ trial (Fig. $5 A)\left(F_{(1,31)}=5.328 ; p<\right.$ $0.05)$. The initial latency to enter the dark compartment after being placed in the light compartment was also significantly longer in translin $\mathrm{KO}$ mice (Fig. $5 B)\left(F_{(1,31)}=4.730 ; p<0.05\right)$. The number of transitions between compartments did not differ
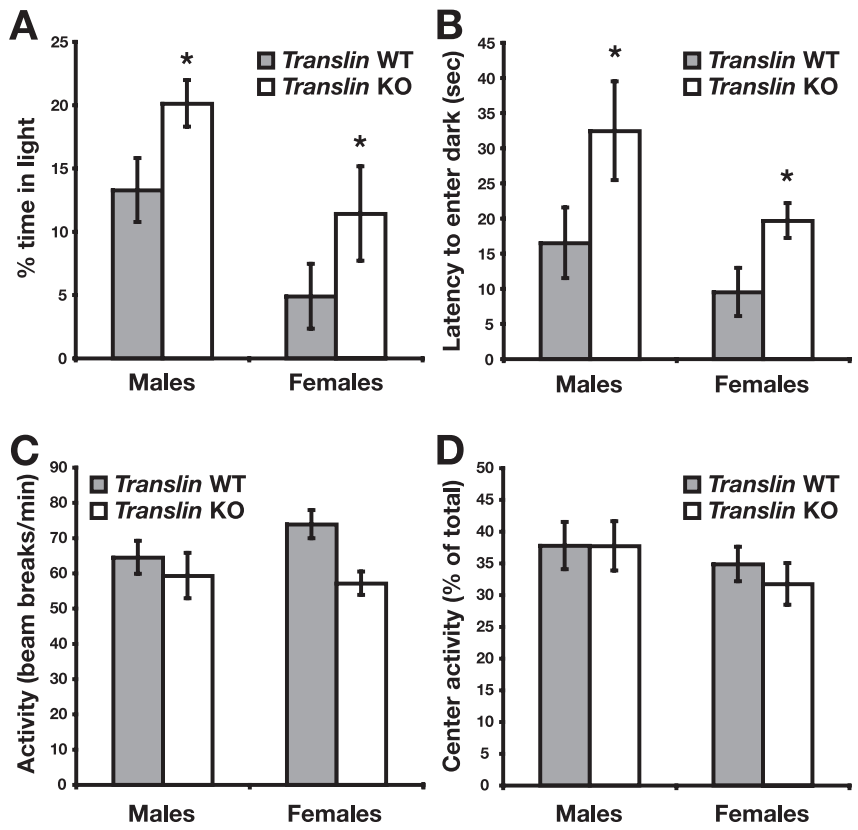

Figure 5. translin KO mice exhibit decreased anxiety-related behavior in the light-dark exploration test and normal baseline locomotor activity in the open field. $\boldsymbol{A}, \boldsymbol{B}$, translin $\mathrm{KO}$ mice ( $n=15,9$ males and 6 females) and WT littermates ( $n=20,14$ males and 6 females) were placed in the center of the open compartment of the light- dark box apparatus and observed for $10 \mathrm{~min}$. $\boldsymbol{A}$, Male mice spent a greater percentage of time in the open compartment than female mice, and, accounting for sex differences, translin $\mathrm{KO}$ mice spent significantly more time in the open than their WT littermates. $\boldsymbol{B}$, The latency to enter the dark compartment was also significantly longer in translin $\mathrm{KO}$ mice, accounting for differences attributable to sex. $\boldsymbol{C}, \boldsymbol{D}$, translin $\mathrm{KO}$ mice ( $n=33,26$ males and 7 females) and WT littermates ( $n=43,34$ males and 9 females) were placed in the center of the open-field arena, and activity was recorded over $15 \mathrm{~min}$ by arrays of photobeams. C, Locomotor activity did not differ significantly between translin KO mice and WT littermates. $\boldsymbol{D}$, Anxiety-related behavior, as assessed by the percentage of total open-field activity that occurred in the central area of the arena, did not differ significantly between genotypes. ${ }^{*} p<0.05$ for WT mice versus KO mice.

between groups (data not shown). One outlier, a male KO mouse, with a latency to enter the dark compartment of $487 \mathrm{~s}$, was excluded from the analysis.

To determine whether baseline locomotor activity is altered in mice lacking translin, we tested translin $\mathrm{KO}$ mice $(n=33,26$ males and 7 females) and WT littermates $(n=43,34$ males and 9 females) in an automated open-field apparatus that records activity using a grid of photobeams. The total activity over $15 \mathrm{~min}$ in the open field as measured by photobeam breaks did not differ significantly between translin $\mathrm{KO}$ and WT animals (Fig. 5C). Because mice tend to stay close to the walls of the open-field chamber and avoid the center area, this test can also be used to measure anxiety-related behavior (Simon et al., 1994); however, despite our observations using the elevated zero maze and the light-dark box test, activity in the center of the open field versus the periphery did not differ significantly between translin $\mathrm{KO}$ mice and WT littermates (Fig. 5D). Male and female mice of both genotypes exhibited higher activity in the periphery, but the center of the chamber may not have been sufficiently anxiogenic to detect anxiety-related differences under the lighting conditions we used. Although we observed jumping behavior in translin $\mathrm{KO}$ mice during training in the Morris water maze, the amount of vertical activity recorded over $15 \mathrm{~min}$ in the open-field apparatus did not differ between genotypes (data not shown). 

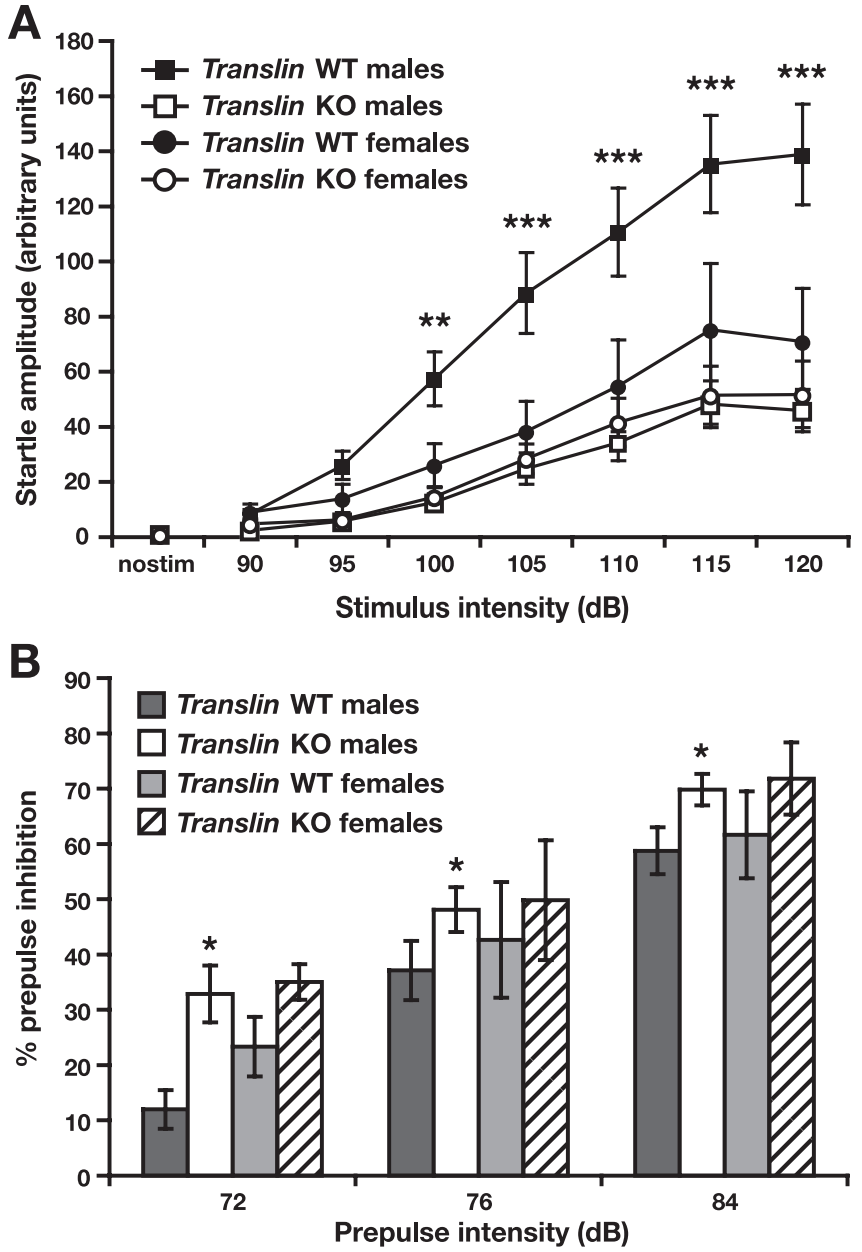

Figure 6. Acoustic startle responses are significantly reduced and prepulse inhibition of startle is significantly increased in translin KO mice. $A$, Male translin KO mice $(n=16)$ exhibit significantly reduced whole-body startle amplitudes relative to male WT littermates $(n=20)$ across a range of stimulus intensities from 100 to $120 \mathrm{~dB}$. Startle responses of female translin $\mathrm{KO}$ mice $(n=9)$ did not differ significantly from female WT littermates $(n=7)$ or male K0 mice. $\boldsymbol{B}$, translin $\mathrm{KO}$ mice exhibit significantly enhanced prepulse inhibition of the startle response relative to WT littermates. There was a significant difference in percentage of prepulse inhibition between male translin $\mathrm{K} 0$ mice and WT littermates at prepulse intensities of 72, 76, and 84 ${ }^{*} p<0.05,{ }^{* *} p<0.01,{ }^{* *} p<0.001$ for male WT mice versus male translin K0 mice.

Acoustic startle responses are reduced and prepulse inhibition is enhanced in male mice lacking translin fmr1 KO mice exhibit reduced startle responses and enhanced prepulse inhibition of the startle response (Chen and Toth, 2001; Nielsen et al., 2002; Frankland et al., 2004). We hypothesized that translin $\mathrm{KO}$ mice would exhibit similar alterations in sensorimotor gating. As expected, startle response amplitudes increased with greater stimulus intensities independently of genotype and sex (Fig. 6A) $\left(F_{(7,329)}=53.463 ; p<0.0001\right)$; however, translin $\mathrm{KO}$ mice exhibited significantly reduced startle amplitudes relative to WT littermates at stimulus intensities from 95 to $120 \mathrm{~dB}$ $\left(F_{(1,47)}=10.579 ; p<0.01\right)$. There were also significant stimulus intensity $\times$ genotype and stimulus intensity $\times$ genotype $\times$ sex interactions $\left(F_{(7,329)}=7.069, p<0.0001 ; F_{(7,329)}=2.602, p<\right.$ 0.05 , respectively). Male translin $\mathrm{KO}$ mice $(n=16)$ exhibited significantly reduced average startle responses relative to male WT littermates $(n=20)$ at all stimulus intensities from 100 to 120 $\mathrm{dB}(100 \mathrm{~dB}, p<0.01 ; 105-120 \mathrm{~dB}, p<0.001)$. The average startle response of female translin $\mathrm{KO}$ mice $(n=9)$ was somewhat less than that of female littermates $(n=7)$ at each stimulus level, but there was not a significant effect of genotype or a genotype by stimulus interaction when considering females alone. In fact, startle responses among females of both genotypes did not differ significantly from male translin $\mathrm{KO}$ mice, which is similar to what Qin et al. (2005) reported in a study including male and female fmrl KO mice. translin KO mice also exhibited significantly enhanced prepulse inhibition of the startle response relative to WT mice (Fig. $6 B)\left(F_{(1,47)}=6.747 ; p<0.05\right)$.

As reported previously, translin $\mathrm{KO}$ mice are significantly smaller than their WT littermates until $\sim 6$ months of age (Chennathukuzhi et al., 2003). On average, both the male and female $\mathrm{KO}$ mice we tested weighed significantly less than their WT littermates (males, $23.1 \pm 1.0$ vs $26.4 \pm 0.7 \mathrm{~g} ; t$ test, $p<0.05$; females, $16.9 \pm 0.8$ vs $22.4 \pm 0.8$ g, $t$ test, $p<0.001)$. Startle measurements are partially dependent on mass but are unlikely to be affected by differences of this magnitude, and average startle amplitude was not correlated with weight by regression analysis. Hearing deficits could possibly account for reductions in startle amplitude; however, translin $\mathrm{KO}$ mice were trained specifically to the $85 \mathrm{~dB}$ white noise used in fear conditioning, and the tones used to evoke startle responses are considerably louder.

\section{Monoamine neurotransmitter levels are altered in multiple forebrain areas in male and female translin $\mathrm{KO}$ mice} The monoaminergic neurotransmitters NE, 5-HT, and DA influence motor activity, anxiety-related behavior, learned fear, and sensorimotor gating in rodents. Differences in monoamine levels have been observed in the absence of FMRP in both mice and Drosophila (Gruss and Braun, 2001, 2004; Zhang et al., 2005). To determine whether differences in monoaminergic neurotransmission may underlie behavioral alterations in translin $\mathrm{KO}$ mice, we used HPLC to measure levels of monoamine neurotransmitters and their metabolites in the amygdala, hippocampus, and cortex in translin $\mathrm{KO}$ mice ( $n=12,7$ males and 5 females) and WT littermate controls ( $n=14,7$ males and 7 females). The amygdala and hippocampus were examined based on their role in mediating learning, fear, and anxiety-related behavior. The PFC and striatum were also analyzed in male mice because of the role of these regions in modulating exploratory behavior, motor activity, and acoustic startle responses.

Male and female translin $\mathrm{KO}$ mice exhibited significant differences in levels of the monoamine neurotransmitters and their metabolites in multiple brain regions. NE was significantly reduced in the hippocampus and cortex in male translin $\mathrm{KO}$ mice (Fig. 7A) (hippocampus, $p<0.01$; cortex, $p<0.05$ ). NE was reduced to a similar extent in the amygdala, but the apparent difference did not reach significance (Fig. $7 A)(p=0.15)$. NE was significantly reduced in the amygdala, hippocampus, and cortex in female translin $\mathrm{KO}$ mice compared with WT littermates (Fig. $7 A$ ) (amygdala, $p<0.01$; hippocampus, $p<0.001$; cortex, $p<$ 0.0001). To determine whether reduced tissue levels of NE reflect decreased production or increased turnover, we also measured the amount of the NE metabolite MHPG in the hippocampus and amygdala in male mice. MHPG was significantly reduced in both brain regions in male translin $\mathrm{KO}$ mice (hippocampus, $0.290 \pm$ 0.030 vs $0.186 \pm 0.011 \mathrm{pmol} / \mathrm{mg}, p<0.01 ;$ amygdala, $0.311 \pm$ 0.044 vs $0.148 \pm 0.014 \mathrm{pmol} / \mathrm{mg}, p<0.01$ ), but $\mathrm{NE}$ turnover as measured by the ratio of MHPG to NE was not significantly altered (hippocampus, $0.124 \pm 0.012$ vs $0.112 \pm 0.007$; amygdala, $0.14 \pm 0.05$ vs $0.09 \pm 0.02$ ), suggesting that NE synthesis is reduced in these brain regions.

Male translin $\mathrm{KO}$ mice also exhibited reductions in 5-HT in the hippocampus, cortex, and striatum relative to WT littermates 

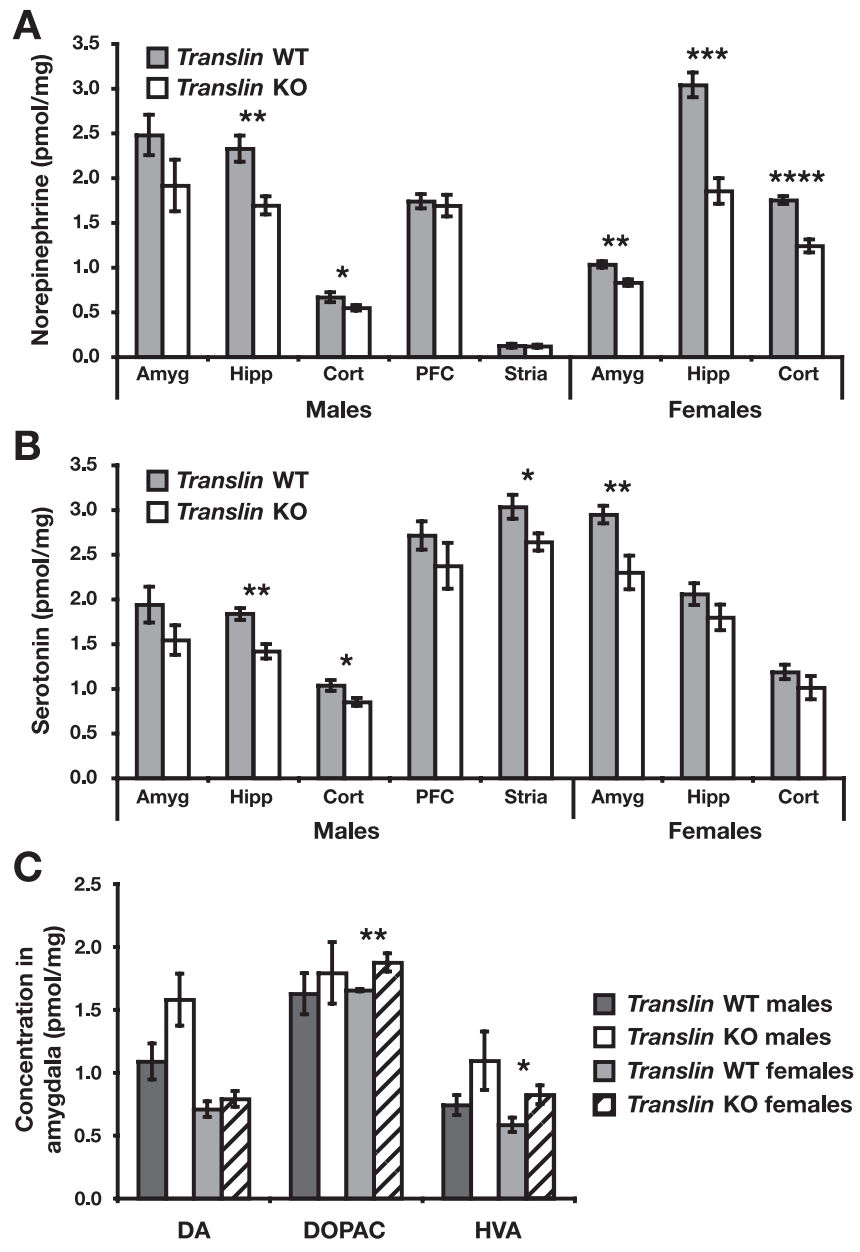

Figure 7. translin $\mathrm{KO}$ mice exhibit alterations in the level of monoamine neurotransmitters in the forebrain. HPLC was used to determine the concentration of the monoamine neurotransmitters NE, 5 -HT, DA, and their metabolites in multiple brain regions in translin $\mathrm{KO}$ mice ( $n=$ 12,7 males and 5 females) and WT littermate controls ( $n=14,7$ males and 7 females). $\boldsymbol{A}$, NE is significantly reduced in the hippocampus and cortex in male translin $\mathrm{KO}$ mice and in the amygdala, hippocampus, and cortex in female translin KO mice. $\boldsymbol{B}, 5$-HT levels are significantly decreased in the hippocampus, cortex, and striatum in male translin $\mathrm{KO}$ mice and in the amygdala in female translin $\mathrm{KO}$ mice. $C$, Levels of DA in the amygdala do not differ between genotypes, but levels of the metabolites DOPAC and HVA are significantly increased in female translin $\mathrm{KO}$ mice. ${ }^{*} p<0.05 ;{ }^{* *} p<0.01$; ${ }^{* * *} p<0.001$; ${ }^{* * * *} p<0.0001$.

(Fig. 7B) (hippocampus, $p<0.01$; cortex, $p<0.05$; striatum, $p<$ $0.05)$. Again, a similar reduction was observed in the amygdala, but the difference did not reach significance because of greater variability in this group of samples (Fig. $7 C)(p=0.15)$. In female translin $\mathrm{KO}$ mice, 5-HT was significantly reduced in the amygdala (Fig. $7 B)(p<0.01)$. We also determined the concentration of the 5-HT metabolite 5-HIAA in each brain area in male and female translin $\mathrm{KO}$ mice and WT littermates. The concentration of 5-HIAA was significantly reduced in the striatum in male translin $\mathrm{KO}$ mice $(2.00 \pm 0.07$ vs $1.75 \pm 0.08 \mathrm{pmol} / \mathrm{mg} ; p<0.05)$ but was not significantly altered in other brain areas or in female mice. Serotonin turnover, as measured by the ratio of 5-HIAA to 5-HT, did not differ significantly between male translin $\mathrm{KO}$ mice and WT littermates in any brain area. However, 5-HT turnover in the amygdala in female translin $\mathrm{KO}$ mice was significantly increased relative to WT littermates $(1.37 \pm 0.13$ vs $1.74 \pm 0.09$; $p<0.05)$.

Levels of DA in the amygdala (Fig. 7C), cortex, PFC, and striatum did not differ between translin KO mice and WT litter- mates, and DA was not reliably detected in the hippocampus; however, concentrations of the DA metabolites DOPAC and HVA were significantly increased in the amygdala in female translin KO mice (Fig. 7C) (DOPAC, $p<0.01$; HVA, $p<0.05$ ). DA turnover can be measure using the following ratios: DOPAC/ DA, HVA/DA, and (DOPAC + HVA)/DA. In male translin $\mathrm{KO}$ mice, there was a trend toward decreased DA turnover in the amygdala, as measured by the ratio of DOPAC to DA (1.57 \pm 0.17 vs $1.15 \pm 0.11 ; p=0.055)$. Increases in the average concentration of both DOPAC and HVA in the amygdala in female translin $\mathrm{KO}$ mice suggest an increase in DA turnover, but there was not a statistically significant increase in turnover in this or any other brain region in female mice using the above measures.

\section{Discussion}

We investigated the behavior of translin KO mice and WT littermates and observed multiple abnormalities, including increased escape latency in the Morris water maze in male KO mice, enhanced fear conditioning in female $\mathrm{KO}$ mice, reduced anxietyrelated behavior in the zero maze and light-dark box in male and female $\mathrm{KO}$ mice, and reduced startle responses and increased prepulse inhibition of startle in male $\mathrm{KO}$ mice. translin $\mathrm{KO}$ mice also exhibit reductions in NE and 5-HT that may explain some of these behavioral differences. Our neurochemical findings indicate that translin may affect the synthesis of monoamine neurotransmitters or signaling pathways activated by monoamine receptor stimulation. Mice lacking FMRP exhibit several similar behavioral and neurochemical alterations, and current theories regarding the function of FMRP suggest a mechanism by which translin may influence monoamine signaling.

\section{Behavioral and neurochemical alterations in translin $\mathrm{KO}$ mice} translin $\mathrm{KO}$ mice exhibit multiple, sex-dependent behavioral differences relative to WT littermates (Table 1). Overall, translin KO mice show decreased anxiety-related responses in the setting of potential threats but exaggerated fear responses and defensive behaviors (freezing, jumping, and escape) when exposed to actual threats. Exaggerated stress responses may lead to enhanced performance in fear conditioning in female $\mathrm{KO}$ mice but interfere with learning and impair performance in the Morris water maze, particularly in male KO mice. Stress-induced hyperactivity, inattention, or a failure to shift search strategies as indicated by persistent thigmotaxis may also contribute to poor performance in the water maze in male $\mathrm{KO}$ mice.

Both male and female translin $\mathrm{KO}$ mice exhibit reductions in $\mathrm{NE}$ and 5-HT, neurotransmitters with prominent roles in regulating fear and anxiety-related behavior. NE released from fibers arising in the locus ceruleus initiates fight-or-flight responses. NE depletion reduces anxiety-related behavior in the plus maze in rats (Lapiz et al., 2001), and mice lacking NE show similar trends in the plus maze and the light-dark box (Marino et al., 2005). 5-HT depletion also reduces anxiety-related behavior in rodents in the elevated plus maze (Treit et al., 1993b) and the light-dark box (Artaiz et al., 1998). In addition, 5-HT depletion increases impulsivity and hyperactivity (Winstanley et al., 2004), which may explain the jumping behavior and stress-induced hyperactivity we observed in translin $\mathrm{KO}$ mice. Interestingly, mice engineered to either lack or overexpress the $5-\mathrm{HT}_{3}$ receptor exhibit reduced anxiety-related behavior in the plus maze but increased fear conditioning (Harrell and Allan, 2003; Bhatnagar et al., 2004). Dopaminergic signaling in the amygdala supports both the formation and expression of conditioned fear (Pezze and Feldon, 2004), and increases in DOPAC and HVA suggest that 
Table 1. Behavioral phenotypes of translin and fmr1 $\mathrm{KO}$ mice

\begin{tabular}{lll}
\hline Behavioral test & translin K0 & fmr1 K0 \\
\hline $\begin{array}{l}\text { Morris water maze } \\
\text { Acquisition }\end{array}$ & Males impaired & Normal $(1-4)$ \\
Reversal & Males impaired & Impaired $(1,2)$, normal $(3)$ \\
Visible & Males impaired & Normal $(1-3)$ \\
Quandrant preference & Normal & Normal $(1-4)$ \\
Fear conditioning & & \\
Immediate freezing & Males increased & Normal $(3-5)$ \\
Contextual freezing & Females increased & Decreased $(3)$, normal $(4,5)$ \\
Cued freezing & Females increased & Decreased $(3)$, normal $(4,5)$ \\
Anxiety-related behavior & & \\
Zero/plus maze & Reduced & Normal $(6,7)$ \\
Light- dark box & Reduced & Reduced $(1-4)$ \\
Open field & Males normal & Reduced $(4,6,8,9)$, normal $(7)$ \\
& Females normal & Females normal $(9)$ \\
Locomotor activity & & \\
Zero/plus maze & Increased & Increased $(6)$, normal $(7)$ \\
Open field & Normal & Increased $(4,6,8,9)$, normal $(7)$ \\
Accelerating rotorod & Mildly impaired $(10)$ & Mildly impaired $(4)$ \\
Acoustic startle & Males reduced & Males reduced $(9,11,12)$ \\
Prepulse inhibition & Females normal & Females normal $(8)$ \\
\hline Both transtin and FMRP & Males increased & Males increased $(9,11,12)$ \\
\hline
\end{tabular}

Both translin and FMRP are thought to regulate mRNA localization and local translation in neurons. Our results reveal behavioral similarities and some differences in mice lacking these proteins. Listed phenotypes are the same for male and female translin $\mathrm{KO}$ mice unless otherwise specified. Results listed for fmr $1 \mathrm{KO}$ mice are for male mice, unless otherwise specified. 1, Bakker et al., 1994; 2, D'Hooge et al., 1997; 3, Paradee et al., 1999; 4, Peier et al., 2000; 5, Van Dam et al., 2000; 6, Mineur et al., 2002; 7, Qin et al., 2002; 8, Qin et al., 2005; 9, Nielsen et al., 2002; 10, Chennathukuzhi et al., 2003; 11, Chen et al., 2001; 12, Frankland et al., 2004

DA turnover is enhanced in female translin $\mathrm{KO}$ mice although it is relatively reduced in male $\mathrm{KO}$ mice.

$\mathrm{NE}$ also modulates attention, cognitive function, sensorimotor gating, and seizure susceptibility. NE is important for selective attention and behavioral flexibility (Aston-Jones and Cohen, 2005), and reduced hippocampal or cortical NE may contribute to water maze impairments in male translin $\mathrm{KO}$ mice. Notably, $\mathrm{NE}$ depletion in wild-type mice and overexpression of $\alpha 2 \mathrm{C}$ adrenoreceptors, which inhibit NE release, in transgenic mice increase thigmotaxis in the water maze (Bjorklund et al., 2000). Loss of locus ceruleus neurons is also associated with decreased startle responses (Von Coelln et al., 2004). Like male translin KOs, mice overexpressing $\alpha 2 \mathrm{C}$ adrenoreceptors show reduced startle and increased PPI, whereas mice lacking these receptors exhibit the opposite effects (Sallinen et al., 1998). Finally, reduced $\mathrm{NE}$ levels may predispose translin $\mathrm{KO}$ mice to seizures because $\mathrm{NE}$ is thought to act as an endogenous anticonvulsant, and mice lacking NE exhibit enhanced seizure susceptibility (Szot et al., 1999).

The various sex-dependent behavioral alterations we observed probably reflect the influence of gonadal hormones and inherent sex differences in stress responses. Differences in learning, activity, and anxiety-related behavior between male and female mice from common inbred strains are well documented (Berger-Sweeney et al., 1995; Bolivar et al., 2001; Voikar et al., 2001; Jonasson, 2005). Notably, there are also behavioral and neurochemical differences between hemizygous male and homozygous female fmr1 KO mice (Gruss and Braun, 2001, 2004; Qin et al., 2005).

Variability attributable to genetic background is always a concern in behavioral studies using genetically modified mice (Crawley et al., 1997). We tested translin KO mice alongside WT littermates to minimize effects of genetic and environmental variability. Although 129 mice perform better in learning tests, they exhibit increased anxiety-related behavior relative to C57BL/6J mice in multiple paradigms (Crawley et al., 1997); thus, background effects cannot readily explain the decreased anxiety-related behavior we observed. Using conventional $\mathrm{KO}$ mice, we cannot determine whether phenotypes result from abnormal development or altered function of adult neurons. Neuroanatomy was indistinguishable from WT mice in all brain regions examined (Chennathukuzhi et al., 2003), but detailed neuronal connectivity has not been investigated. Furthermore, because the genetic manipulation is not restricted to a specific brain region or cell type, $\mathrm{KO}$ phenotypes may reflect the interplay of multiple regions and systems. Finally, the absence of translin in peripheral tissues, such as the adrenal glands, thyroid gland, or gonads, may affect behavior.

\section{Similarities to $\mathrm{fmr} 1 \mathrm{KO}$ mice and potential relevance to human disease}

Translin and FMRP have many functional similarities at the cellular level, and our results reveal behavioral similarities in mice lacking these proteins (Table 1). Like translin $\mathrm{KO}$ mice, fmrl KOs exhibit alterations in tests of activity and anxietyrelated behavior, motor function, and sensorimotor gating. fmrl KO mice show combinations of hyperactivity and reduced anxiety-related behavior in the open-field test, the light-dark box, and the elevated plus maze (Bakker et al., 1994; Peier et al., 2000). translin and fmr1 KO mice demonstrate nearly identical phenotypes in the accelerating rotarod test (Peier et al., 2000; Chennathukuzhi et al., 2003) and show similar reductions in startle responses and enhancements in prepulse inhibition (Chen and Toth, 2001; Nielsen et al., 2002; Frankland et al., 2004). fmr1 KO mice also exhibit enhanced susceptibility to audiogenic seizures (Chen and Toth, 2001). We observed seizures in translin KO mice, but additional studies will be needed to quantitatively evaluate seizure susceptibility.

Mental retardation is a prominent component of fragile $\mathrm{X}$ syndrome, but learning deficits in the water maze and fear conditioning have been inconsistently observed in mice lacking FMRP and may be related to genetic background effects (Dobkin et al., 2000). Deficits have been reported recently in trace fear conditioning (Zhao et al., 2005) and the object recognition task (Ventura et al., 2004). In both cases, the poor performance of fmrl $\mathrm{KO}$ mice was attributed to impaired attention, which is consistent with attention deficits observed in fragile X syndrome in humans and a potential role for attention deficits in male translin $\mathrm{KO}$ mice. Abnormalities in monoamine signaling are implicated in attention deficit hyperactivity disorder (Faraone et al., 2005; Pliszka, 2005) and observed in both FMRP and translin KO mice. Although few alterations in monoamine neurotransmitters are detected in male fmr $1 \mathrm{KO}$ mice at baseline (Gruss and Braun, 2001), they exhibit altered dopamine release after amphetamine treatment (Ventura et al., 2004). Female fmr1 KO mice exhibit baseline reductions in 5-HT and DA and changes in 5-HT and DA turnover in multiple forebrain regions (Gruss and Braun, 2004). Unfortunately, there are no reports investigating $\mathrm{NE}$ levels in fmr1 KO mice. Interestingly, fruit flies lacking the Drosophila homolog of FMRP have increased brain levels of both 
5-HT and DA and increased expression and activity of enzymes involved in monoamine synthesis (Zhang et al., 2005).

Recent theories regarding neurotransmitter abnormalities in fragile $\mathrm{X}$ syndrome have focused on alterations in metabotropic glutamate receptor (mGluR) signaling (Bear et al., 2004) rather than monoamine neurotransmitters. However, Weiler et al. (2004) recently showed that FMRP acts downstream of protein kinase C (PKC) to regulate mGluR-dependent local translation, suggesting that the absence of FMRP may affect other neurotransmitter systems, including NE, 5-HT, and DA, with receptor subtypes that signal through PKC (Miyashiro and Eberwine, 2004). Like FMRP, translin may regulate local translation downstream of PKC activation, and misregulation in its absence may lead to compensatory changes in monoamine synthesis. Interestingly, translin is downregulated in the cortex of rats after chronic treatment with the NE and 5-HT reuptake inhibitor imipramine (Palotas et al., 2004), which may reflect a role for translin downstream of monoamine receptor stimulation.

Unfortunately, the relevant neuronal mRNA targets of FMRP and translin are not known. Studies using microarrays, RNA selection, and antibody-associated RNA amplification have identified numerous transcripts that may interact with FMRP (Brown et al., 2001; Darnell et al., 2001; Miyashiro et al., 2003), but these approaches have not yet been applied to translin. Direct evidence linking mutations in translin to disease in humans is also currently lacking. Mutations at the fragile X site are relatively common and exposed in the hemizygous condition, whereas mutations in translin would require homozygosity on human chromosome 2 and produce disease much more rarely. Nevertheless, our results in mice suggest that mutations affecting translin expression or function may contribute to behavioral and developmental disorders in humans, including fragile X-like syndromes, mental retardation, attention deficit hyperactivity disorder, epilepsy, and autism spectrum disorders.

\section{References}

Antar LN, Dictenberg JB, Plociniak M, Afroz R, Bassell GJ (2005) Localization of FMRP-associated mRNA granules and requirement of microtubules for activity-dependent trafficking in hippocampal neurons. Genes Brain Behav 4:350-359.

Artaiz I, Zazpe A, Del Rio J (1998) Characterization of serotonergic mechanisms involved in the behavioural inhibition induced by 5-hydroxytryptophan in a modified light-dark test in mice. Behav Pharmacol 9:103-112.

Aston-Jones G, Cohen JD (2005) An integrative theory of locus coeruleusnorepinephrine function: adaptive gain and optimal performance. Annu Rev Neurosci 28:403-450.

Bakker C, Verheij C, Willemsen R, van der Helm R, Oerlemans F, Vermey M, Bygrave A, Hoogeveen AT, Oostra BA, Reyniers E, De Boule K, D'Hooge R, Cras P, van Velzen D, Nagels G, Martin J-J, De Deyn PP, Darby JK, Willems PJ (1994) Fmrl knockout mice: a model to study fragile X mental retardation. Cell 78:23-33.

Baldi E, Lorenzini CA, Bucherelli C (2004) Footshock intensity and generalization in contextual and auditory-cued fear conditioning in the rat. Neurobiol Learn Mem 81:162-166.

Bear MF, Huber KM, Warren ST (2004) The mGluR theory of fragile X mental retardation. Trends Neurosci 27:370-377.

Berger-Sweeney J, Arnold A, Gabeau D, Mills J (1995) Sex differences in learning and memory in mice: effects of sequence of testing and cholinergic blockade. Behav Neurosci 109:859-873.

Bhatnagar S, Nowak N, Babich L, Bok L (2004) Deletion of the 5-HT3 receptor differentially affects behavior of males and females in the Porsolt forced swim and defensive withdrawal tests. Behav Brain Res 153:527-535.

Bjorklund M, Sirvio J, Riekkinen M, Sallinen J, Scheinin M, Riekkinen Jr P (2000) Overexpression of alpha2C-adrenoceptors impairs water maze navigation. Neuroscience 95:481-487.
Bolivar VJ, Pooler O, Flaherty L (2001) Inbred strain variation in contextual and cued fear conditioning behavior. Mamm Genome 12:651-656.

Bontekoe CJ, McIlwain KL, Nieuwenhuizen IM, Yuva-Paylor LA, Nellis A, Willemsen R, Fang Z, Kirkpatrick L, Bakker CE, McAninch R, Cheng NC, Merriweather M, Hoogeveen AT, Nelson D, Paylor R, Oostra BA (2002) Knockout mouse model for Fxr2: a model for mental retardation. Hum Mol Genet 11:487-498.

Brown V, Jin P, Ceman S, Darnell JC, O'Donnell WT, Tenenbaum SA, Jin X, Feng Y, Wilkinson KD, Keene JD, Darnell RB, Warren ST (2001) Microarray identification of FMRP-associated brain mRNAs and altered mRNA translational profiles in fragile X syndrome. Cell 107:477-487.

Caudy AA, Myers M, Hannon GJ, Hammond SM (2002) Fragile X-related protein and VIG associate with the RNA interference machinery. Genes Dev 16:2491-2496.

Chen L, Toth M (2001) Fragile X mice develop sensory hyperreactivity to auditory stimuli. Neuroscience 103:1043-1050.

Chennathukuzhi V, Stein JM, Abel T, Donlon S, Yang S, Miller JP, Allman DM, Simmons RA, Hecht NB (2003) Mice deficient for testis-brain RNA-binding protein exhibit a coordinate loss of TRAX, reduced fertility, altered gene expression in the brain, and behavioral changes. Mol Cell Biol 23:6419-6434.

Crawley JN, Belknap JK, Collins A, Crabbe JC, Frankel W, Henderson N, Hitzemann RJ, Maxson SC, Miner LL, Silva AJ, Wehner JM, WynshawBoris A, Paylor R (1997) Behavioral phenotypes of inbred mouse strains: implications and recommendations for molecular studies. Psychopharmacology (Berl) 132:107-124.

Darnell JC, Jensen KB, Jin P, Brown V, Warren ST, Darnell RB (2001) Fragile X mental retardation protein targets $\mathrm{G}$ quartet mRNAs important for neuronal function. Cell 107:489-499.

D’Hooge R, Nagels G, Franck F, Bakker CE, Reyniers E, Storm K, Kooy RF, Oostra BA, Willems PJ, De Deyn PP (1997) Mildly impaired water maze performance in male Fmr1 knockout mice. Neuroscience 76:367-376.

Dobkin C, Rabe A, Dumas R, El Idrissi A, Haubenstock H, Brown WT (2000) Fmrl knockout mouse has a distinctive strain-specific learning impairment. Neuroscience 100:423-429.

Ecker DJ, Stein P, Xu Z, Williams CJ, Kopf GS, Bilker WB, Abel T, Schultz RM (2004) Long-term effects of culture of preimplantation mouse embryos on behavior. Proc Natl Acad Sci USA 101:1595-1600.

Faraone SV, Perlis RH, Doyle AE, Smoller JW, Goralnick JJ, Holmgren MA, Sklar P (2005) Molecular genetics of attention-deficit/hyperactivity disorder. Biol Psychiatry 57:1313-1323.

Feng Y, Gutekunst CA, Eberhart DE, Yi H, Warren ST, Hersch SM (1997) Fragile X mental retardation protein: nucleocytoplasmic shuttling and association with somatodendritic ribosomes. J Neurosci 17:1539-1547.

Finkenstadt PM, Kang WS, Jeon M, Taira E, Tang W, Baraban JM (2000) Somatodendritic localization of Translin, a component of the Translin/ Trax RNA binding complex. J Neurochem 75:1754-1762.

Finkenstadt PM, Jeon M, Baraban JM (2001) Masking of the Translin/Trax complex by endogenous RNA. FEBS Lett 498:6-10.

Frankland PW, Wang Y, Rosner B, Shimizu T, Balleine BW, Dykens EM, Ornitz EM, Silva AJ (2004) Sensorimotor gating abnormalities in young males with fragile X syndrome and Fmr1-knockout mice. Mol Psychiatry 9:417-425.

Gould TJ, Bizily SP, Tokarczyk J, Kelly MP, Siegel SJ, Kanes SJ, Abel T (2004) Sensorimotor gating deficits in transgenic mice expressing a constitutively active form of Gs alpha. Neuropsychopharmacology 29:494-501.

Gruss M, Braun K (2001) Alterations of amino acids and monoamine metabolism in male Fmr1 knockout mice: a putative animal model of the human fragile X mental retardation syndrome. Neural Plast 8:285-298.

Gruss M, Braun K (2004) Age- and region-specific imbalances of basal amino acids and monoamine metabolism in limbic regions of female Fmr1 knock-out mice. Neurochem Int 45:81-88.

Gu W, Wu XQ, Meng XH, Morales C, el-Alfy M, Hecht NB (1998) The RNA- and DNA-binding protein TB-RBP is spatially and developmentally regulated during spermatogenesis. Mol Reprod Dev 49:219-228.

Han JR, Yiu GK, Hecht NB (1995a) Testis/brain RNA-binding protein attaches translationally repressed and transported mRNAs to microtubules. Proc Natl Acad Sci USA 92:9550-9554.

Han JR, Gu W, Hecht NB (1995b) Testis-brain RNA-binding protein, a testicular translational regulatory RNA-binding protein, is present in the brain and binds to the $3^{\prime}$ untranslated regions of transported brain $\mathrm{mR}$ NAs. Biol Reprod 53:707-717. 
Harrell AV, Allan AM (2003) Improvements in hippocampal-dependent learning and decremental attention in $5-\mathrm{HT}_{3}$ receptor overexpressing mice. Learn Mem 10:410-419.

Hergersberg M, Matsuo K, Gassmann M, Schaffner W, Luscher B, Rulicke T, Aguzzi A (1995) Tissue-specific expression of a FMR1/betagalactosidase fusion gene in transgenic mice. Hum Mol Genet 4:359-366.

Ishizuka A, Siomi MC, Siomi H (2002) A Drosophila fragile X protein interacts with components of RNAi and ribosomal proteins. Genes Dev 16:2497-2508.

Jonasson Z (2005) Meta-analysis of sex differences in rodent models of learning and memory: a review of behavioral and biological data. Neurosci Biobehav Rev 28:811-825.

Kobayashi S, Takashima A, Anzai K (1998) The dendritic translocation of translin protein in the form of $\mathrm{BC} 1 \mathrm{RNA}$ protein particles in developing rat hippocampal neurons in primary culture. Biochem Biophys Res Commun 253:448-453.

Kwon YK, Hecht NB (1993) Binding of a phosphoprotein to the 3' untranslated region of the mouse protamine 2 mRNA temporally represses its translation. Mol Cell Biol 13:6547-6557.

Laggerbauer B, Ostareck D, Keidel EM, Ostareck-Lederer A, Fischer U (2001) Evidence that fragile X mental retardation protein is a negative regulator of translation. Hum Mol Genet 10:329-338.

Lapiz MD, Mateo Y, Durkin S, Parker T, Marsden CA (2001) Effects of central noradrenaline depletion by the selective neurotoxin DSP-4 on the behaviour of the isolated rat in the elevated plus maze and water maze. Psychopharmacology (Berl) 155:251-259.

Lattal KM, Abel T (2001) Different requirements for protein synthesis in acquisition and extinction of spatial preferences and context-evoked fear. J Neurosci 21:5773-5780.

Lewejohann L, Skryabin BV, Sachser N, Prehn C, Heiduschka P, Thanos S, Jordan U, Dell'Omo G, Vyssotski AL, Pleskacheva MG, Lipp HP, Tiedge H, Brosius J, Prior H (2004) Role of a neuronal small non-messenger RNA: behavioural alterations in BC1 RNA-deleted mice. Behav Brain Res 154:273-289.

Li Z, Zhang Y, Ku L, Wilkinson KD, Warren ST, Feng Y (2001) The fragile X mental retardation protein inhibits translation via interacting with mRNA. Nucleic Acids Res 29:2276-2283.

Lin DY, Wei LJ (1989) The robust inference for the Cox proportional hazards model. J Am Stat Assoc 84:1074-1078.

Marino MD, Bourdelat-Parks BN, Cameron Liles L, Weinshenker D (2005) Genetic reduction of noradrenergic function alters social memory and reduces aggression in mice. Behav Brain Res 161:197-203.

Miller S, Yasuda M, Coats JK, Jones Y, Martone ME, Mayford M (2002) Disruption of dendritic translation of CaMKIIalpha impairs stabilization of synaptic plasticity and memory consolidation. Neuron 36:507-519.

Mineur YS, Sluyter F, de Wit S, Oostra BA, Crusio WE (2002) Behavioral and neuroanatomical characterization of the Fmr1 knockout mouse. Hippocampus 12:39-46.

Miyakawa T, Yared E, Pak JH, Huang FL, Huang KP, Crawley JN (2001) Neurogranin null mutant mice display performance deficits on spatial learning tasks with anxiety related components. Hippocampus 11:763-775.

Miyashiro K, Eberwine J (2004) Fragile X syndrome: (What's) lost in translation? Proc Natl Acad Sci USA 101:17329-17330.

Miyashiro KY, Beckel-Mitchener A, Purk TP, Becker KG, Barret T, Liu L, Carbonetto S, Weiler IJ, Greenough WT, Eberwine J (2003) RNA cargoes associating with FMRP reveal deficits in cellular functioning in Fmr 1 null mice. Neuron 37:417-431.

Morales CR, Lefrancois S, Chennathukuzhi V, El-Alfy M, Wu X, Yang J, Gerton GL, Hecht NB (2002) A TB-RBP and Ter ATPase complex accompanies specific mRNAs from nuclei through the nuclear pores and into intercellular bridges in mouse male germ cells. Dev Biol 246:480-494.

Morris RG, Garrud P, Rawlins JN, O'Keefe J (1982) Place navigation impaired in rats with hippocampal lesions. Nature 297:681-683.

Muramatsu T, Ohmae A, Anzai K (1998) BC1 RNA protein particles in mouse brain contain two $y$-,h-element-binding proteins, translin and a 37 kDa protein. Biochem Biophys Res Commun 247:7-11.

Nie T, Abel T (2001) Fear conditioning in inbred mouse strains: an analysis of the time course of memory. Behav Neurosci 115:951-956.
Nielsen DM, Derber WJ, McClellan DA, Crnic LS (2002) Alterations in the auditory startle response in Fmr1 targeted mutant mouse models of fragile X syndrome. Brain Res 927:8-17.

Ohashi S, Koike K, Omori A, Ichinose S, Ohara S, Kobayashi S, Sato TA, Anzai $\mathrm{K}$ (2002) Identification of mRNA/protein (mRNP) complexes containing Puralpha, mStaufen, fragile $\mathrm{X}$ protein, and myosin Va and their association with rough endoplasmic reticulum equipped with a kinesin motor. J Biol Chem 277:37804-37810.

Onaivi ES, Martin BR (1989) Neuropharmacological and physiological validation of a computer-controlled two-compartment black and white box for the assessment of anxiety. Prog Neuropsychopharmacol Biol Psychiatry 13:963-976.

Palotas M, Palotas A, Puskas LG, Kitajka K, Pakaski M, Janka Z, Molnar J, Penke B, Kalman J (2004) Gene expression profile analysis of the rat cortex following treatment with imipramine and citalopram. Int J Neuropsychopharmacol 7:401-413.

Paradee W, Melikian HE, Rasmussen DL, Kenneson A, Conn PJ, Warren ST (1999) Fragile X mouse: strain effects of knockout phenotype and evidence suggesting deficient amygdala function. Neuroscience 94:185-192.

Peier AM, McIlwain KL, Kenneson A, Warren ST, Paylor R, Nelson DL (2000) (Over)correction of FMR1 deficiency with YAC transgenics: behavioral and physical features. Hum Mol Genet 9:1145-1159.

Pezze MA, Feldon J (2004) Mesolimbic dopaminergic pathways in fear conditioning. Prog Neurobiol 74:301-320.

Phillips RG, LeDoux JE (1992) Differential contribution of amygdala and hippocampus to cued and contextual fear conditioning. Behav Neurosci 106:274-285.

Pliszka SR (2005) The neuropsychopharmacology of attention-deficit/hyperactivity disorder. Biol Psychiatry 57:1385-1390.

Qin M, Kang J, Smith CB (2002) Increased rates of cerebral glucose metabolism in a mouse model of fragile X mental retardation. Proc Natl Acad Sci USA 99:15758-15763.

Qin M, Kang J, Smith CB (2005) A null mutation for Fmrl in female mice: effects on regional cerebral metabolic rate for glucose and relationship to behavior. Neuroscience 135:999-1009.

Robinson MB, Heyes MP, Anegawa NJ, Gorry E, Djali S, Mellits ED, Batshaw ML (1992) Quinolinate in brain and cerebrospinal fluid in rat models of congenital hyperammonemia. Pediatr Res 32:483-488.

Sallinen J, Haapalinna A, Viitamaa T, Kobilka BK, Scheinin M (1998) Adrenergic $\alpha 2 \mathrm{C}$-receptors modulate the acoustic startle reflex, prepulse inhibition, and aggression in mice. J Neurosci 18:3035-3042.

Schenk F, Morris RG (1985) Dissociation between components of spatial memory in rats after recovery from the effects of retrohippocampal lesions. Exp Brain Res 58:11-28.

Severt WL, Biber TU, Wu X, Hecht NB, DeLorenzo RJ, Jakoi ER (1999) The suppression of testis-brain RNA binding protein and kinesin heavy chain disrupts mRNA sorting in dendrites. J Cell Sci 112:3691-3702.

Shepherd JK, Grewal SS, Fletcher A, Bill DJ, Dourish CT (1994) Behavioural and pharmacological characterisation of the elevated "zero-maze" as an animal model of anxiety. Psychopharmacology (Berl) 116:56-64.

Simon P, Dupuis R, Costentin J (1994) Thigmotaxis as an index of anxiety in mice. Influence of dopaminergic transmissions. Behav Brain Res 61:59-64.

Szot P, Weinshenker D, White SS, Robbins CA, Rust NC, Schwartzkroin PA, Palmiter RD (1999) Norepinephrine-deficient mice have increased susceptibility to seizure-inducing stimuli. J Neurosci 19:10985-10992.

Treit D, Menard J, Royan C (1993a) Anxiogenic stimuli in the elevated plusmaze. Pharmacol Biochem Behav 44:463-469.

Treit D, Robinson A, Rotzinger S, Pesold C (1993b) Anxiolytic effects of serotonergic interventions in the shock-probe burying test and the elevated plus-maze test. Behav Brain Res 54:23-34.

Van Dam D, D'Hooge R, Hauben E, Reyniers E, Gantois I, Bakker CE, Oostra BA, Kooy RF, De Deyn PP (2000) Spatial learning, contextual fear conditioning and conditioned emotional response in Fmr1 knockout mice. Behav Brain Res 117:127-136.

Ventura R, Pascucci T, Catania MV, Musumeci SA, Puglisi-Allegra S (2004) Object recognition impairment in Fmrl knockout mice is reversed by amphetamine: involvement of dopamine in the medial prefrontal cortex. Behav Pharmacol 15:433-442.

Voikar V, Koks S, Vasar E, Rauvala H (2001) Strain and gender differences in the behavior of mouse lines commonly used in transgenic studies. Physiol Behav 72:271-281. 
Von Coelln R, Thomas B, Savitt JM, Lim KL, Sasaki M, Hess EJ, Dawson VL, Dawson TM (2004) Loss of locus coeruleus neurons and reduced startle in parkin null mice. Proc Natl Acad Sci USA 101:10744-10749.

Wang J, Boja ES, Oubrahim H, Chock PB (2004) Testis brain ribonucleic acid-binding protein/translin possesses both single-stranded and doublestranded ribonuclease activities. Biochemistry 43:13424-13431.

Weiler IJ, Spangler CC, Klintsova AY, Grossman AW, Kim SH, BertainaAnglade V, Khaliq H, de Vries FE, Lambers FA, Hatia F, Base CK, Greenough WT (2004) Fragile X mental retardation protein is necessary for neurotransmitter-activated protein translation at synapses. Proc Natl Acad Sci USA 101:17504-17509.

Winstanley CA, Theobald DE, Dalley JW, Glennon JC, Robbins TW (2004) 5-HT2A and 5-HT2C receptor antagonists have opposing effects on a measure of impulsivity: interactions with global 5-HT depletion. Psychopharmacology (Berl) 176:376-385.

Wolfer DP, Stagljar-Bozicevic M, Errington ML, Lipp HP (1998) Spatial memory and learning in transgenic mice: fact or artifact? News Physiol Sci 13:118-123.

Wu XQ, Hecht NB (2000) Mouse testis brain ribonucleic acid-binding protein/translin colocalizes with microtubules and is immunoprecipitated with messenger ribonucleic acids encoding myelin basic protein, alpha calmodulin kinase II, and protamines 1 and 2. Biol Reprod 62:720-725.
Wu XQ, Petrusz P, Hecht NB (1999) Testis-brain RNA-binding protein (Translin) is primarily expressed in neurons of the mouse brain. Brain Res 819:174-178.

Yang J, Chennathukuzhi V, Miki K, O’Brien DA, Hecht NB (2003) Mouse testis brain RNA-binding protein/translin selectively binds to the messenger RNA of the fibrous sheath protein glyceraldehyde 3-phosphate dehydrogenase-S and suppresses its translation in vitro. Biol Reprod 68:853-859.

Zalfa F, Giorgi M, Primerano B, Moro A, Di Penta A, Reis S, Oostra B, Bagni C (2003) The fragile $\mathrm{X}$ syndrome protein FMRP associates with BC1 RNA and regulates the translation of specific mRNAs at synapses. Cell 112:317-327.

Zeger SL, Liang KY (1986) Longitudinal data analysis for discrete and continuous outcomes. Biometrics 42:121-130.

Zhang YQ, Friedman DB, Wang Z, Woodruff III E, Pan L, O’Donnell J, Broadie K (2005) Protein expression profiling of the Drosophila fragile X mutant brain reveals up-regulation of monoamine synthesis. Mol Cell Proteomics 4:278-290.

Zhao MG, Toyoda H, Ko SW, Ding HK, Wu LJ, Zhuo M (2005) Deficits in trace fear memory and long-term potentiation in a mouse model for fragile X syndrome. J Neurosci 25:7385-7392. 